\title{
Principles and properties of ion flow in P2X receptors
}

\section{Damien S. K. Samways ${ }^{1 *}$, Zhiyuan Li $^{2}$ and Terrance M. Egan ${ }^{3}$}

1 Department of Biology, Clarkson University, Potsdam, NY, USA

${ }^{2}$ Guangzhou Institute of Biomedicine and Health, University of Chinese Academy of Sciences, Guangzhou, China

${ }^{3}$ Department of Pharmacological and Physiological Science, The Center for Excellence in Neuroscience, Saint Louis University School of Medicine, St. Louis, MO, USA

\section{Edited by:}

Baljit S. Khakh, University of California Los Angeles, USA

\section{Reviewed by:}

Thomas Grutter, University of Strasbourg - CNRS, France

Samuel J. Fountain, University of

East Anglia, UK

\section{*Correspondence:}

Damien S. K. Samways, Department

of Biology, Clarkson University,

8 Clarkson Avenue, Potsdam,

NY 13699, USA

e-mail: samwaysds@s/u.edu
P2X receptors are a family of trimeric ion channels that are gated by extracellular adenosine 5 'triphosphate (ATP). These receptors have long been a subject of intense research interest by virtue of their vital role in mediating the rapid and direct effects of extracellular ATP on membrane potential and cytosolic $\mathrm{Ca}^{2+}$ concentration, which in turn underpin the ability of ATP to regulate a diverse range of clinically significant physiological functions, including those associated with the cardiovascular, sensory, and immune systems. An important aspect of an ion channel's function is, of course, the means by which it transports ions across the biological membrane. A concerted effort by investigators over the last two decades has culminated in significant advances in our understanding of how P2X receptors conduct the inward flux of $\mathrm{Na}^{+}$and $\mathrm{Ca}^{2+}$ in response to binding by ATP. However, this work has relied heavily on results from current recordings of P2X receptors altered by site-directed mutagenesis. In the absence of a 3-dimensional channel structure, this prior work provided only a vague and indirect appreciation of the relationship between structure, ion selectivity and flux. The recent publication of the crystal structures for both the closed and open channel conformations of the zebrafish P2X4 receptor has thus proved a significant boon, and has provided an important opportunity to overview the amassed functional data in the context of a working 3-dimensional model of a P2X receptor. In this paper, we will attempt to reconcile the existing functional data regarding ion permeation through $\mathrm{P} 2 \mathrm{X}$ receptors with the available crystal structure data, highlighting areas of concordance and discordance as appropriate.

Keywords: P2X, ATP, permeability, selectivity, gating, mutagenesis, SCAM

\section{INTRODUCTION}

The P2X receptors are a family of seven (P2X1R-P2X7R) cation permeable ligand-gated ion channels (LGICs) that open in response to binding by the extracellular ligand, adenosine $5^{\prime}$ triphosphate (ATP). In contrast to tetrameric ionotropic glutamate receptors and pentameric Cys-loop receptors, the P2XRs are assembled from three peptide subunits (Nicke et al., 1998; Stoop et al., 1999; Jiang et al., 2003; Barrera et al., 2005). Each subunit is comprised of intracellular amino and carboxyl termini linked via two transmembrane-spanning helices (TM1 and TM2) to a large extracellular ligand-binding domain (Newbolt et al., 1998; Torres et al., 1998a,b). Binding of ATP to a site in the extracelluar domain elicits a global conformational change that ultimately leads to the opening of a pore through which cations freely move into and out of the cell (Baconguis and Gouaux, 2012; Hattori and Gouaux, 2012). With the exception of P2X6R, all the subunits assemble into functional homomeric ion channels. In addition, several heteromeric assemblies have been identified and characterized, including the P2X2/3R functionally expressed in pain-processing neurons (Lewis et al., 1995; Le et al., 1998; Torres et al., 1998c, 1999; King et al., 2000; Aschrafi et al., 2004;

Abbreviations: ATP, adenosine 5'-triphosphate; SCAM, scanning cysteine accessibility method; LGIC, ligand-gated ion channel.
Compan et al., 2012). P2XRs exhibit little discrimination between $\mathrm{Na}^{+}$and $\mathrm{K}^{+}$but, at resting membrane potentials, currents are chiefly carried by movement of $\mathrm{Na}^{+}$down its electrochemical gradient and into the cell. The result is membrane depolarization. All P2XRs also conduct $\mathrm{Ca}^{2+}$, with the permeability of $\mathrm{Ca}^{2+}$ relative to $\mathrm{Na}^{+}\left(\mathrm{P}_{\mathrm{Ca}} / \mathrm{P}_{\mathrm{Na}}\right)$ varying depending on the subunit make-up of the functional channel (Egan and Khakh, 2004). Thus, the two initial consequences of P2XR activation to cellular signaling are a $\mathrm{Na}^{+}$-mediated depolarization of the plasma membrane, and an increase in the concentration of free cytosolic $\mathrm{Ca}^{2+}\left(\left[\mathrm{Ca}^{2+}\right]_{i}\right)$. These two results subsequently influence action potential propagation and affect a myriad of $\mathrm{Ca}^{2+}$-sensitive processes, including secretion (Khakh and Henderson, 2000; Norenberg et al., 2001), muscle contraction (Lamont and Wier, 2002; Brain et al., 2003), and cell survival (for review see Di Virgilio, 2012; Volonte et al., 2012).

Over the last two decades, an exhaustive effort to relate P2XR structure to the function of these channels has provided a good understanding of how ATP transduces current across the plasma membrane. Multiple laboratories have successfully utilized molecular biological techniques and patch clamp electrophysiology to identify amino acids necessary for ligand binding, signal transduction and ion permeation. Nevertheless, the successful crystallization of a zebrafish P2X4.1R, in both the closed 
(Kawate et al., 2009; PDB ID 4DW0) and ATP-bound open (Hattori and Gouaux, 2012; PDB ID 4DW1) conformations was a dramatic advance for the field. On the one hand, these structures serve as the basis of a slew of new testable hypotheses about the relationship between P2XR structure and function. On the other, they provide an all-important 3-dimensional template upon which to review and interpret previously obtained functional data. Many of the most important advances are described in numerous reviews (Egan et al., 2006; Khakh and North, 2006; Roberts et al., 2006; Burnstock and Kennedy, 2011; Coddou et al., 2011; Kaczmarek-Hajek et al., 2012; North and Jarvis, 2013). This review focuses entirely on the following two questions: (1) How do ions enter the pore of a P2XR and subsequently transition from one side of the plasma membrane to the other? (2) How do $\mathrm{P} 2 \mathrm{XRs}$ discriminate between ions, selecting and permeating some to a greater degree than others? With these questions in mind, the principle objective of this review is to view the data obtained from functional studies over the last two decades within the context of the now available 3-dimensional crystal structures, particularly that of the open channel state, in order to gauge the degree of concordance and potentially identify areas of inconsistency. As a visual aid, a number of figures are included which serve to simply map the results of various systematic functional studies onto the relevant $\mathrm{P} 2 \mathrm{XR}$ structure. We have also included a sequence alignment showing examples of human and rat P2XRs for reference (Figure 1). Most of the studies investigating ion permeation and selection in this family of ion channels were conducted on the P2X2R and P2X4R. Homology models for these receptors were generated based on the available crystallographic data obtained for the truncated zebrafish P2X4.1R.

\section{EXTRACELLULAR ACCESS TO THE TRANSMEMBRANE CHANNEL PORE}

The initial publication of the closed channel structure for the zebrafish $\mathrm{P} 2 \mathrm{X} 4 \mathrm{R}$ revealed the presence of three lateral portals, or fenestrations, situated in the extracellular domain proximal to the outer leaflet of the lipid bilayer (Kawate et al., 2009). The diameter of these lateral portals, equal to $\sim 12 \AA$, is sufficient to allow for the passage of water and fully hydrated ions, and provoked the compelling hypothesis that they might serve as the primary access points for extracellular ions to approach the mouth of the transmembrane pore itself. The closed structure also indicated the presence of three cavities within the extracellular domain of the receptor, which Kawate et al. (2009) designated the upper, central and extracellular vestibules (Figure 2). These form a broken chain along the central axis of the receptor, and present an alternative ion conduction hypothesis in which the central pathway widens during gating to form a single pore running the entire length of the protein. Further, Kawate et al. saw a gadolinium ion $\left(\mathrm{Gd}^{3+}\right)$ coordinated in the central vestibule of zebrafish $\mathrm{P} 2 \mathrm{X} 4.1 \mathrm{R}$, and used patch clamp electrophysiology to show that $\mathrm{Gd}^{3+}$ inhibited ATP-gated current. However, it did

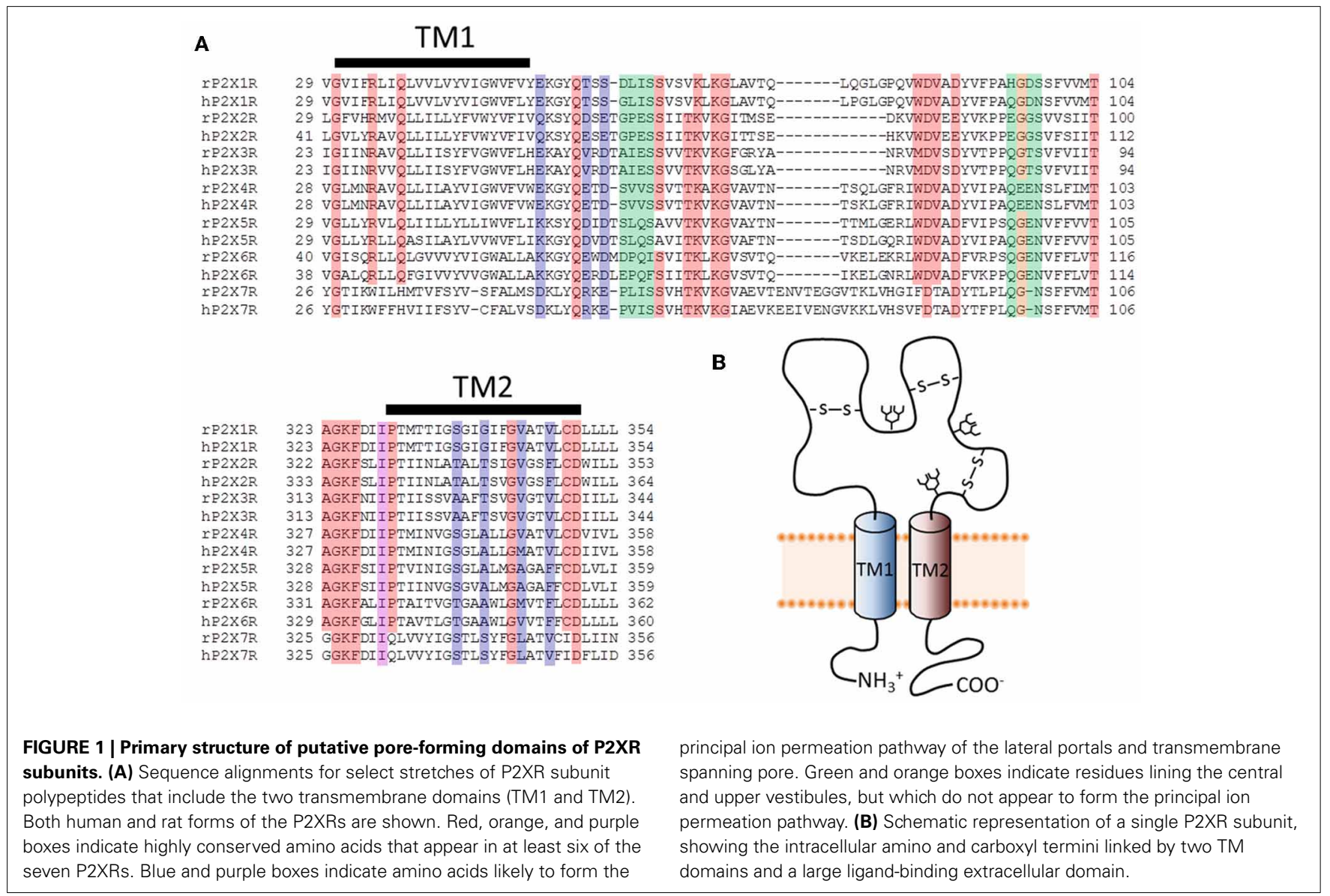




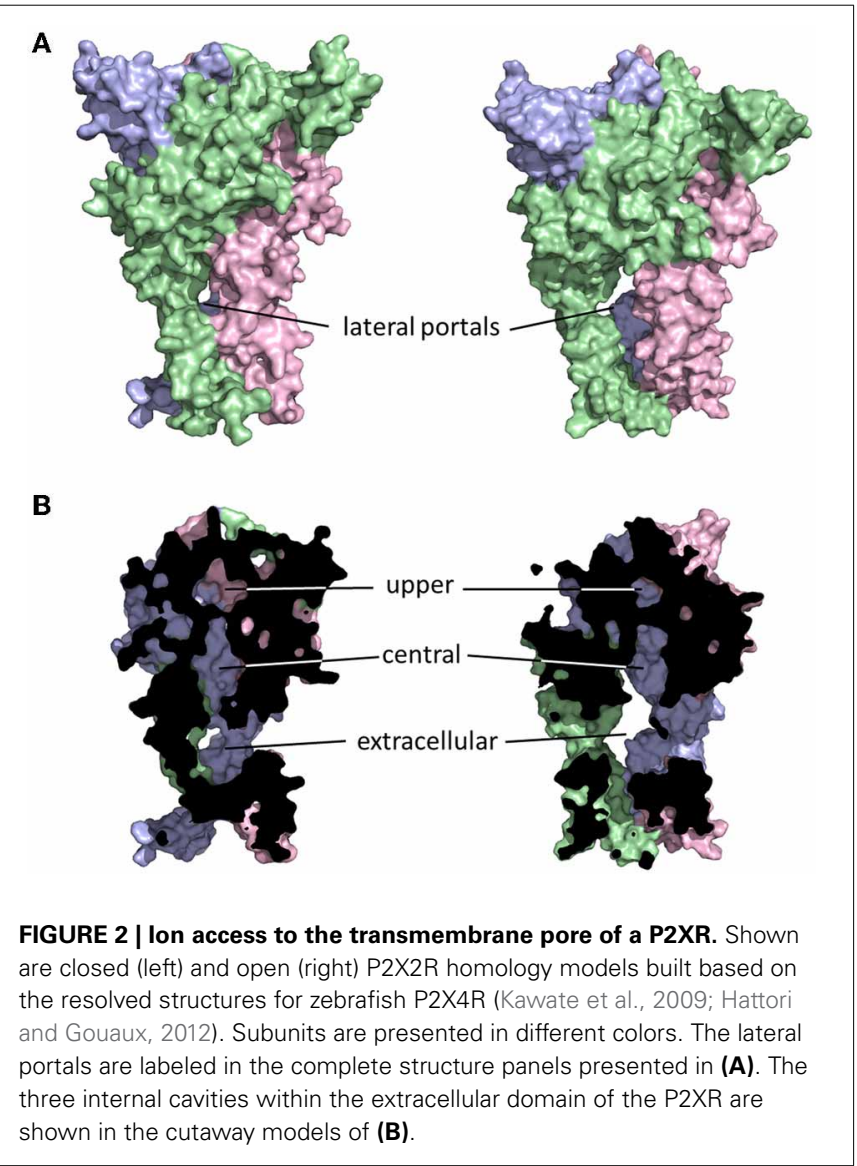

so in a manner that was surmountable by increasing the concentration of ATP, suggesting that the inhibition of current was not caused by $\mathrm{Gd}^{3+}$ occluding an ionic conduction pathway. Indeed, the fact that current still flowed through the P2X4.1R even when the central vestibule was inhibited by a $\mathrm{Gd}^{3+}$ ion suggested that ion entry occurs below this point in the structure. Furthermore, the closed structure shows at least two barriers to ion movement along the central pathway that would have to open in order to allow permeation. The presence of extracellular gates that impede ion flow was not predicted from the results of numerous experiments that used the Scanning Cysteine Accessibility Method (SCAM) to identify differences in solvent accessibility of open and closed channels (Egan et al., 1998; Jiang et al., 2001; Kracun et al., 2010; Li et al., 2010). Indeed, the use of the SCAM in $\mathrm{P} 2 \mathrm{X} 2 \mathrm{R}$ and $\mathrm{P} 2 \mathrm{X} 4 \mathrm{R}$ revealed that cysteine substitutions introduced into the upper vestibule were not rapidly accessible to modification by thiol-reactive methanethiosulfonate (MTS) compounds (Kawate et al., 2011; Samways et al., 2011). Kawate et al. (2011) produced a double-cysteine mutant P2X2R containing a disulfide bond across the central axis of the central vestibule, which did nothing to impair ion flow. To the contrary, currents through the channel were inhibited rather than potentiated by reduction of the S-S bond with dithiothreitol (DTT) suggesting that while movement in this region might be important for gating, it is highly unlikely that it contributes to the ion conductions pathway.
The lateral pore hypothesis was largely validated by the publication of the ATP-bound open channel structure of zfP2X4R (Hattori and Gouaux, 2012). As the rat P2X2R homology model in Figure 2 suggests, these lateral portals expand during gating, in agreement with predictions made on the basis of functional experiments (Kawate et al., 2011; Samways et al., 2011). In the open structure state, the upper vestibule seems to remain isolated from the bulk solution, but the central and extracellular vestibules appear to merge to form a single large inner cavity that extends into the opened transmembrane ion conducting pathway. The merging of the central and extracellular vestibules concords with functional data, with cysteine substitutions introduced at positions within the central vestibule in P2X1R, P2X2R, and P2X4R being accessible to water-soluble thiol-reactive agents in the open state. Specifically, currents through P2X1R-G60C, P2X2R-I317C, and P2X2R-H319C, and P2X4R-S62C and P2X4R-N97C, were all modified by the positively charged thiol-reactive MTS reagent, MTSET $^{+}$(Kawate et al., 2011; Samways et al., 2011). However, the currents through four of these mutants, P2X1R-G60C, P2X2RH319C, P2X4R-E56C, and P2X4R-D58C, were potentiated rather than suppressed by MTSET $^{+}$modification.

The central vestibule has a negative electrostatic surface potential (Kawate et al., 2009, 2011). It also shows some charge discrimination, as seen in its ability to discriminate between cationic and anionic MTS compounds. Brief $3 \mathrm{~s}$ exposure to the anionic MTS reagent, MTSES $^{-}$, had no effect on currents mediated by P2X4R-S62C and P2X4R-N97C, and more importantly did not prevent subsequent $\mathrm{MTSET}^{+}$exposure from potentiating currents (Samways et al., 2011), indicating that only the positively charged molecule could access and modify these sites. On the other hand, much longer applications $(\sim 60 \mathrm{~s})$ were sufficient for MTSES $^{-}$to modify cysteines introduced in the same region of P2X2R (Jiang et al., 2010). Nevertheless, MTSES ${ }^{-}$can readily and rapidly modify cysteines introduced intracellular to this region within the lateral portals and as far down into the transmembrane pore as positions Ser ${ }^{341}$ in P2X4R (Samways et al., 2011) and $\mathrm{Thr}^{336}$ in P2X2R (Rassendren et al., 1997), adding weight to the idea that thiol-reactive agents enter the extracellular vestibule through the lateral portals.

The possibility that $\mathrm{P} 2 \mathrm{XRs}$ might inhabit conformational states in which ions can intrude into the central pathway cannot be completely ruled out. SCAM studies of P2X1R showed that longer (5-60 $\mathrm{min}$ ) incubations with thiol-reactive reagents were sufficient to cause modification of upper vestibule positions (Allsopp et al., 2011; Roberts et al., 2012a), indicating that these areas are not completely sealed from the surrounding aqueous environment. Based on free energy calculations and the closed zebrafish P2X4.1R crystal structure, Kawate et al. (2011) estimated that a modest widening of the central axis pore during gating could feasibly provide a sufficient permeation pathway favorable for $\mathrm{Na}^{+}$conduction, but found that this was not so for the P2X2R homology model due to differences in primary amino acid sequence within this region of the receptor. Along similar lines, Roberts et al. (2012a,b), showed that the cysteines introduced into the upper vestibule of P2X1R were more easily accessed and modified by N-Biotinoylaminoethyl-MTSEA in the absence of ATP than in the presence, suggesting that, although 
this region might be weakly accommodating of water and ions in the closed state, it becomes much less so in the open state, further ruling out this region as a key ion conducting pathway in the open channel. Thus, the lateral portals remain the most obvious route of entry for ions based on both the available crystallographic data and results from functional studies.

The relatively large size of the lateral portals in the open state crystal structure has invited some surprise, particularly due to the degree to which these portals appear to invade the lipid bilayer, and the seeming lack of contact between intersubunit helices (Figure 2). There would appear to be little to prevent the intrusion of lipids into the ion conducting pathway, and this contention is supported in a recent study from Heymann et al. (2013). Here, molecular dynamics simulations of the open $\mathrm{P} 2 \mathrm{X} 4 \mathrm{R}$ incorporated into a lipid bilayer revealed rapid intrusion of lipid molecules into the permeation pathway, resulting in a hydrophobic barrier to ion permeation that was complete within less than $80 \mathrm{~ns}$. The authors noted that a minor reorientation of the TM2 domains was sufficient to produce an open state model that retained a stable water soluble pathway through the lipid bilayer, without producing a conformation at odds with previously published functional data.

Direct functional evidence for ion entry through the lateral portals has been shown by several groups utilizing SCAM. In $\mathrm{P} 2 \mathrm{X} 4 \mathrm{R}$, cysteines introduced at positions $\mathrm{Glu}^{56}$ and $\mathrm{Asp}^{58}$ lining the lateral portals were found to be accessible to modification by $\mathrm{MTSET}^{+}$, which significantly inhibited transmembrane currents in these mutants in a manner that was only reversed by exposure to the reducing agent, DTT (Samways et al., 2011). This inhibition of current was observed whether ATP was present during modification or not, implying that thiol-reactive reagents can penetrate these lateral portals even in the closed state. A cysteine substituted at position $\mathrm{Thr}^{57}$ of $\mathrm{P} 2 \mathrm{X} 1 \mathrm{R}$, a lateral portal-lining residue analogous to $\mathrm{Glu}^{56}$ in P2X4R, was likewise found to be accessible to the large thiol-reactive molecule, N-Biotinoylaminoethyl-MTSEA, in both the closed and open states (Roberts et al., 2012a). Curiously, MTS-modification of cysteines introduced at positions $\mathrm{Thr}^{57}$ and $\mathrm{Ser}^{59}$ in P2X1R had no significant functional effect on the ATPgated current amplitude (Allsopp et al., 2011), and the same lack of effect was reported for the analogous experiments in P2X2R (Kawate et al., 2011). Nevertheless, cysteines introduced at other lateral portal-lining positions in $\mathrm{P} 2 \mathrm{X} 1 \mathrm{R}$ and $\mathrm{P} 2 \mathrm{X} 2 \mathrm{R}$ have been shown to be accessible to and modified by thiol-reactive agents, including Gly ${ }^{60}, \mathrm{Gly}^{321}$, and Ile ${ }^{328}$ of P2X1R (Roberts and Evans, 2007; Allsopp et al., 2011), and Lys ${ }^{53}, \mathrm{Ser}^{54}, \mathrm{Leu}^{327}$, and $\mathrm{Ile}^{328}$ of P2X2R (Rassendren et al., 1997; Egan et al., 1998; Haines et al., 2001). Based on the P2X2R homology model, $\mathrm{Ile}^{328}$ lies between the extracellular vestibules and the lateral portals and, in agreement with the suggestion from the available crystal structural that the lateral portals enlarge substantially during gating, the mutant receptor P2X2-I328C was only modified by the large bulky thiolreactive agent, Texas Red-MTSEA, when the channel was in the open state (Kawate et al., 2011).

The relatively large size of the lateral portals in the closed state $(\sim 12 \AA)$ suggests that they do not form an appreciable barrier to permeation (Kawate et al., 2009), a fact supported by the ability of thiol-reactive agents to access and modify cysteines introduced as deep down into the TM domain as $\mathrm{Thr}^{336}$ (P2X2R) even when the channel is closed ( $\mathrm{Li}$ et al., 2010). As a result, hydrated ions and water can likely diffuse freely between the bulk solution and the extracellular vestibule regardless of whether the P2XR is gated by ATP or not. When the ATP-bound P2XR opens, the ions can then immediately enter the external mouth of the channel pore and begin their journey across the opened transmembrane pore inwards toward the cytosolic space.

\section{TRANSMEMBRANE ION CONDUCTION PATHWAY}

By necessity, actual ion conduction across the plasma membrane proper must involve the parts of a channel protein embedded in the lipid bilayer. For most ion channels, part or all of the permeation pathway is lined by fully transmembrane spanning $\alpha$-helices, with a subset of ion channels having an additional reentrant pore loop dipping into the membrane from the extraor intracellular side (MacKinnon, 2003). Although the initial cloning and sequence analysis of a P2XR suggested the presence of a re-entrant pore loop just extracellular to TM2 (Brake et al., 1994; Valera et al., 1995), subsequent functional studies, and now the available crystal structures, clearly demonstrate that this is not the case. The conventional wisdom has been that more than three TM helices are required in order to assemble a transmembrane pore of sufficient diameter to allow passage of ions (Spencer et al., 2002). Given that each P2XR subunit only has two putative transmembrane domains, there was a distinct possibility that both the TM1 and TM2 domains might to some extent contribute to the pore. This is in contrast to the tetra- and pentameric LGICs, the ionotropic glutamate receptors and Cys-loop channels, in which each of the four or five subunits is only required to contribute a single $\alpha$-helical TM domain to the formation of permeation pathway (Keramidas et al., 2004; Traynelis et al., 2010). Over a decade prior to the successful crystallization and structural resolution of the zfP2XR, significant progress was made in determining the approximate role of these TM domains in ion conduction through this family of ion channels. Once the approximate amino acid sequences contributing to the transmembrane domains were identified (Newbolt et al., 1998; Torres et al., 1998b), SCAM was employed to identify the specific parts of these domains likely to contribute to the lining of the ion conduction pathway.

It is of particular importance to ascertain the degree of concordance between functional studies conducted on TM mutant P2XRs and the 3-dimensional crystal structures for two reasons. First, it is recognized that the lipid bilayer plays an important role in the packing and stability of membrane-spanning proteins, and so the absence of lipid in the crystal structures may have resulted in an abnormal arrangement of the TM domain helices relative to the P2XR in its native environment (see Zhou and Cross, 2013; Heymann et al., 2013). Second, there was a practical necessity to use a truncated version of the $\mathrm{zfP} 2 \mathrm{X} 4 \mathrm{R} .1$ that lacked the cytoplasmic termini for crystallization (Kawate et al., 2009). Functional experiments suggest that the intracellular domains are of considerable importance to the normal functioning of P2XRs, and so it is important to confirm that their removal has not unduly affected the normal arrangement of the TM domains of these proteins within the lipid bilayer (Boue-Grabot et al., 2000; Ennion and Evans, 2002; Yan et al., 2008; Nicke et al., 2009; Roberts et al., 
2012b; and see Costa-Junior et al., 2011). This said, as we believe will be clear from the following discussion, the available functional data actually correlates relatively well with the available crystal structure data.

\section{LIMITED CONTRIBUTION OF TM1}

If a part of TM1 lines the ion conduction pathway, then we would predict that cysteine substitutions introduced into at least some of the positions in this domain would be rapidly accessed and modified by water-soluble thiol-reactive agents when the channel is in the ATP-bound open state. Cysteines introduced at five positions in and near the TM1 domain of P2X2R, $\mathrm{His}^{33}, \mathrm{Arg}^{34}, \mathrm{Ile}^{50}$, $\mathrm{Lys}^{53}$, and Ser ${ }^{54}$, produced mutant receptors with currents sensitive to modification by short, $5 \mathrm{~s}$ co-applications of $\mathrm{Ag}^{+}$and ATP (Haines et al., 2001) (Figure 3). $\mathrm{Ag}^{+}$can coordinate thiol-groups, and its small size allows it to penetrate into small, potentially pore-lining, cavities (Lu and Miller, 1995). These side chains are located on the intra- and extracellular extremes of TM1, with Lys $^{53}$ and Ser ${ }^{54}$ actually residing outside the plain of the plasma membrane, and provides little evidence that TM1 contributes significantly to the transmembrane permeation pathway proper. That cysteines introduced into TM1 are not rapidly accessible to thiol-reactive agents was later confirmed by a subsequent study which failed to observe open channel current modification in all but one mutant, $\mathrm{P} 2 \mathrm{X} 2 \mathrm{R}-\mathrm{V} 48 \mathrm{C}$, in response to a brief $10 \mathrm{~s}$ exposure to the larger thiol-reactive agent, $\operatorname{MTSET}^{+}$(Li et al., 2010) (Figure 3, green).

Nevertheless, although the TM1 domains do not have a primary role in forming the ion conduction pathway, they do not appear to be sealed from the water-soluble pore completely, because longer exposures to thiol-reactive agents were found to be sufficient to uncover a few additional hits within this region. Cysteines substituted into P2X2R positions $\mathrm{Gly}^{30}, \mathrm{Gln}^{37}, \mathrm{Tyr}^{43}$, and $\mathrm{Phe}^{44}$ produced mutants with currents modified by a minute long exposure to thiol-reactive agents (Jiang et al., 2001; Samways

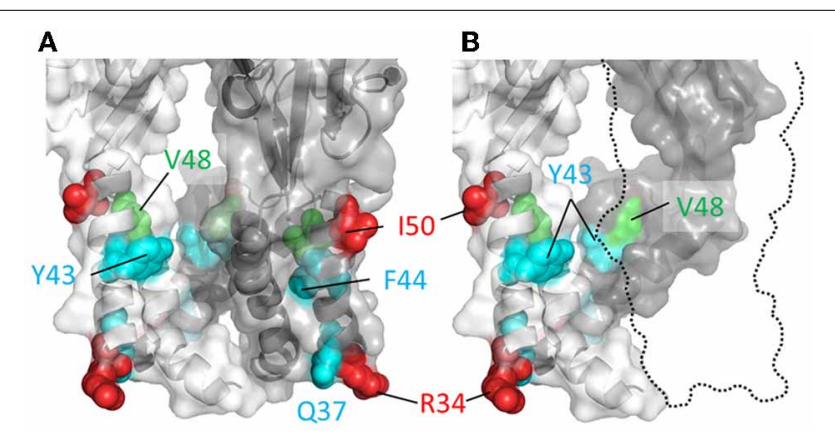

FIGURE 3 | Mapping P2X2R TM1 side-chains accessible to water-soluble thiol-reactive agents using SCAM. TM domain regions shown with all subunits present (A) or the third subunit omitted (B). Side chains at which cysteine substitution renders the mutant receptor sensitive to current modification by thiol-reactive agents are shown as ball models. Color coordination is as follows: Red, mutant currents modified by brief $5 \mathrm{~s}$ application of $\mathrm{Ag}^{+}$only; Green, mutant currents modified by brief $10 \mathrm{~s}$ application to MTSET $^{+}$; Cyan, mutant currents modified by prolonged (>1 $\mathrm{min}$ ) exposure to thiol-reactive reagents. et al., 2008a) (Figure 3, cyan). The limited role of the TM1 domain in forming the narrow part of the transmembrane ion conduction path has largely been confirmed by the open channel P2XR crystal structure, which as we explain next is mostly formed by TM2 helices. That said, the extracellular extremes of TM1, including $\mathrm{Val}^{48}$, do appear to line the wider part of the extracellular pore opening. Indeed, from the structure it is possible to imagine how cysteines introduced at positions $\mathrm{Tyr}^{43}$ and $\mathrm{Phe}^{44}$ might have some limited accessibility to water-soluble thiol-reactive agents. These residues are located at the base the enlarged lateral portal in the open state and, although positioned far from the central axis of the conduction pathway, they may be near or possibly in contact with the water-filled cavity (Figure 3, but also see the refined P2X2R model of Heymann et al., 2013).

\section{ROLE OF TM2}

The TM2 domain was the initial focus of attempts to define the transmembrane ion permeation pathway for P2XRs, because early sequence analysis suggested that this region might connect with an extracellular re-entrant pore loop, not unlike that found in potassium channels (Brake et al., 1994; Valera et al., 1994). Although subsequent functional studies did not provide supporting evidence for the pore-loop hypothesis, systematic probing of the TM2 domain using SCAM presented highly compelling evidence that this was the primary pore-forming part of the P2XR subunit, which concords completely with the available crystal structures (Kawate et al., 2009; Hattori and Gouaux, 2012). In contrast to the TM1 of P2X2R, SCAM uncovered numerous hits along the length of TM2, including contiguous stretches that were confusing due to being seemingly inconsistent with this domain possessing a static helical structure (Rassendren et al., 1997; Egan et al., 1998) (Figure 4). Indeed, cysteines introduced at every single side chain between $\mathrm{Thr}^{336}$ and $\mathrm{Phe}^{346}$ have been reported to be accessible to modification by thiol-reactive compounds by one study or more (Rassendren et al., 1997; Egan et al., 1998; Li et al., 2008, 2010). However, the size of the thiol-reactive agent used and/or long durations of exposure could lead to thiolmodification of side chains that are either located in small protein cavities removed from the permeation pathway, or that are only accessible in rarely visited structural conformations.

Rassendren et al. (1997), tested the effects of three thiolreactive agents, $\mathrm{MTSEA}^{+}, \mathrm{MTSET}^{+}$and $\mathrm{MTSES}^{-}$on current elicited through mutant $\mathrm{P} 2 \mathrm{X} 2 \mathrm{Rs}$ containing cysteine substitutions within TM2. Using an experimental approach in which the thiol-reactive reagents were constantly present during pulsatile ATP applications, and thus exposed to the open and closed channel conformations, it was found that $>30 \mathrm{~s}$ long applications of $\mathrm{MTSEA}^{+}$significantly modified currents through the mutant receptors, I328C, N333C, T336C, L338C, S340C, G342C, and D349C. With the exception of S340C and G342C, in which currents were potentiated by MTSEA ${ }^{+}$, the effect of MTSEA $^{+}$ was inhibitory. Only three of these mutants, I328C, N333C, and T336C, also showed sensitivity to $\mathrm{MTSET}^{+}$and $\mathrm{MTSES}^{-}$, both of which evoked inhibitory effects on channel current in each mutant (Figure 4, blue and cyan). In a later study, the acute effects of a $10 \mathrm{~s}$ application of $\mathrm{MTSET}^{+}$on open channel currents through TM2 cysteine mutants confirmed that I328C and 


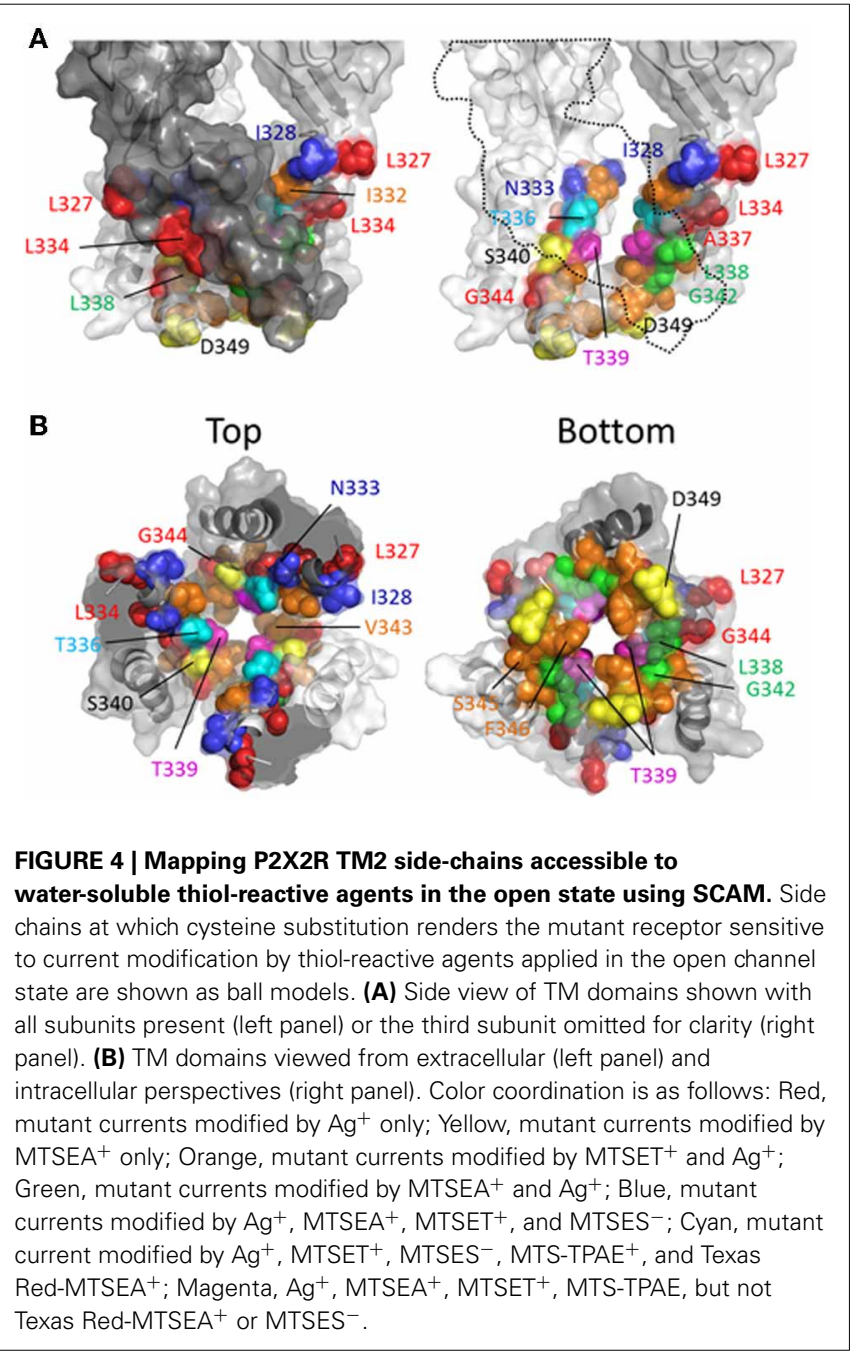

T336C were readily accessible to this thiol-reactive reagent ( $\mathrm{Li}$ et al., 2008). This latter study identified several additional positions that, upon cysteine substitution, were readily accessible to $\mathrm{MTSET}^{+}$in the open state within this short time frame, $\mathrm{Ile}^{332}$, $\mathrm{Thr}^{339}, \mathrm{Ile}^{341}, \mathrm{Val}^{343}, \mathrm{Ser}^{345}$, and $\mathrm{Phe}^{346}$. Consistent with the identification of $\mathrm{Gly}^{342}, \mathrm{Ser}^{345}$, and $\mathrm{Asp}^{349}$ in P2X2R as facing the aqueous environment, the substitution of cysteines for the analogous residues of P2X7R, Gly ${ }^{345}$, $\mathrm{Thr}^{348}$, and $\mathrm{Asp}^{352}$, also yielded mutants accessible to thiol-modification (Browne et al., 2013).

Investigating the stretch of TM2 between $\mathrm{Leu}^{327}$ and $\mathrm{Met}^{356}$ in P2X2R, the Egan laboratory (Egan et al., 1998) probed the accessibility of cysteines substituted into TM2 with $\mathrm{Ag}^{+}$, focusing on the open state of the channel in the presence of ATP. They found that ATP-gated currents through the following P2X2R mutants were rapidly modified by $\mathrm{Ag}^{+}(<5 \mathrm{~s})$ : L327C, I328C, N333C, L334C, T336C, A337C, L338C, T339C, G342C, V343C, G344C, S345C, L352C, and L353C. Fast $\mathrm{Ag}^{+}$modification of currents mediated by N333C, T336C, A337C, T339C, V343C, and S345C were also observed in another laboratory, in addition to hits for I332C, A335C, I341C, and F346C (Li et al., 2008, 2010). It is perhaps not surprising that $\mathrm{Ag}^{+}$could access and modify so many more side chains, as this relatively small ion can potentially enter narrow gaps between protein interfaces that are otherwise inaccessible to the larger thiol-reactive reagents such as $\mathrm{MTSET}^{+}$. We must, of course acknowledge the caveat of using SCAM that a lack of effect of a thiol-reactive agent on the current evoked through a mutant bearing an introduced cysteine is not necessarily evidence that the side chain is inaccessible to that thiol-reactive agent. Nevertheless, mapping the various hits for the different thiolreactive agents presents a convenient pattern that seems mostly consistent with the crystal structure data (Figure 4). Thus, the three mutant P2X2Rs with currents modified by $\mathrm{Ag}^{+}, \mathrm{MTSEA}^{+}$, MTSET $^{+}$, and MTSES ${ }^{-}$, are I328C, N333C, and T336C, which line the wide outer part of the transmembrane pore (Figure 4). The side chain of $\mathrm{Thr}^{336}$ is also accessible to the very large thiolreactive agents 2-tripentylaminoethyl MTS $\left(\mathrm{MTS}_{\mathrm{TPAE}}{ }^{+}\right.$) and Texas Red-MTSEA ${ }^{+}$(Li et al., 2010). In contrast, substituting a cysteine for $\mathrm{Thr}^{339}$ (Figure 4, magenta) renders channel currents sensitive to $\mathrm{Ag}^{+}, \mathrm{MTSEA}^{+}, \mathrm{MTSET}^{+}$, and MTS-TPAE ${ }^{+}$, but not MTSES $^{-}$and Texas Red-MTSEA ${ }^{+}$(Rassendren et al., 1997; Li et al., 2010), suggesting that, consistent with the open channel crystal structure, the pore narrows at this point. Cysteines substituted for Leu ${ }^{338}$ and $\mathrm{Gly}^{342}$ rendered currents sensitive only to the small thiol-reactive agents $\mathrm{Ag}^{+}$and MTSEA ${ }^{+}$(Figure 4, green), which fits with their off-axis orientation toward the narrow opening between intersubunit TM2 domains. Leu ${ }^{334}$, $\mathrm{Ala}^{337}$ and $\mathrm{Gly}^{344}$ are located in tight gaps forming the interfaces between transmembrane helices, and so it perhaps makes sense that cysteines substituted at these positions render mutant currents sensitive only to $\mathrm{Ag}^{+}$(Figure 4, red).

It is interesting that thiol-modification of S340C and G342C potentiates rather than inhibits ATP-gated currents through these mutant P2X2Rs. A similar observation was made for G342C when $\mathrm{Cd}^{2+}$ was used as the thiol-reactive probe (Kracun et al., 2010). Both side chains are positioned slightly off the pore axis in the open crystal structure, so it is conceivable that introduction of a covalent or coordinate bonded molecule here does not obstruct the ion permeation pathway, but instead might disrupt the normal gating equilibrium of the ligand-bound receptor. In P2X7R, substitution of $\mathrm{Gly}^{345}$ (analogous to Gly ${ }^{342}$, P2X2R) produced a mutant with ATP-gated currents that were modestly inhibited by MTSEA ${ }^{+}$and MTSEA-biotin applied in the open state (Browne et al., 2013), possibly indicative of subtle differences in TM domain configuration between P2XRs.

More recent studies have employed SCAM in combination with $\mathrm{Cd}^{2+}$ as the thiol-reactive probe. $\mathrm{Cd}^{2+}$ ions can form coordinate interactions with Cys and His side chains (Kurz et al., 1995; Krovetz et al., 1997; Liu et al., 1997; Holmgren et al., 1998). Ion channel mutants with Cys substituted at positions that orientate toward the central pore axis can potentially coordinate permeating $\mathrm{Cd}^{2+}$, leading to current block. This can assist in identifying side chains forming the narrow regions of the transmembrane pore. Two studies identified TM2 positions at which cysteine substitutions rendered the resulting $\mathrm{P} 2 \mathrm{X} 2 \mathrm{R}$ mutant sensitive to $\mathrm{Cd}^{2+}$ block: I332C, T336C, T339C, G342C, V343C, D349C, and L353C (Kracun et al., 2010; Li et al., 2010), although there were some discrepancies. The mutant F346C was non-functional in Kracun et al's study (Kracun et al., 2010), whereas Li et al. successfully 
recorded currents from this receptor and demonstrated $\mathrm{Cd}^{2+}$ sensitivity (Li et al., 2010). Li et al. also reported $\mathrm{Cd}^{2+}$ sensitivity in the S345C mutant, which was not found to be inhibited by $\mathrm{Cd}^{2+}$ in the other study. Finally, Kracun et al. identified only one mutant that was irreversibly inhibited by $\mathrm{Cd}^{2+}, \mathrm{D} 349 \mathrm{C}$, whereas Li et al., observed irreversible $\mathrm{Cd}^{2+}$ block in the mutants, V343C, S345C, and F346C. Minor discrepancies aside, the combined observations of Kracun et al. and Li et al. are largely consistent with the open channel crystal structure (Figure 5). The sulfhydryl groups of neighboring Cys side chains must be $\sim 5 \AA$ apart in order to be bridged effectively by $\mathrm{Cd}^{2+}$ (the coordinate bond formed between $\mathrm{Cd}^{2+}$ and each Cys side chain being $\sim 2.5 \AA$ ) (Dokmanic et al., 2008). Taking into account the length of the Cys side chain, $\sim 3 \AA$, one would predict that the backbone $\alpha$-carbons of amino acid positions in which Cys substitution would favor coordination of $\mathrm{Cd}^{2+}$ in the central axis of the pore would need to be within $\sim 10 \AA$ of each other. The closed P2X2R homology model shows the distance between the intersubunit $\alpha$-carbons of position $\mathrm{Val}^{343}(\sim 17 \AA)$ and $\mathrm{Phe}^{346}(\sim 24 \AA)$ to be excessive for $\mathrm{Cd}^{2+}$ bridge formation. However, as the channel gates into the open conformation, these side chains come into much closer proximity,

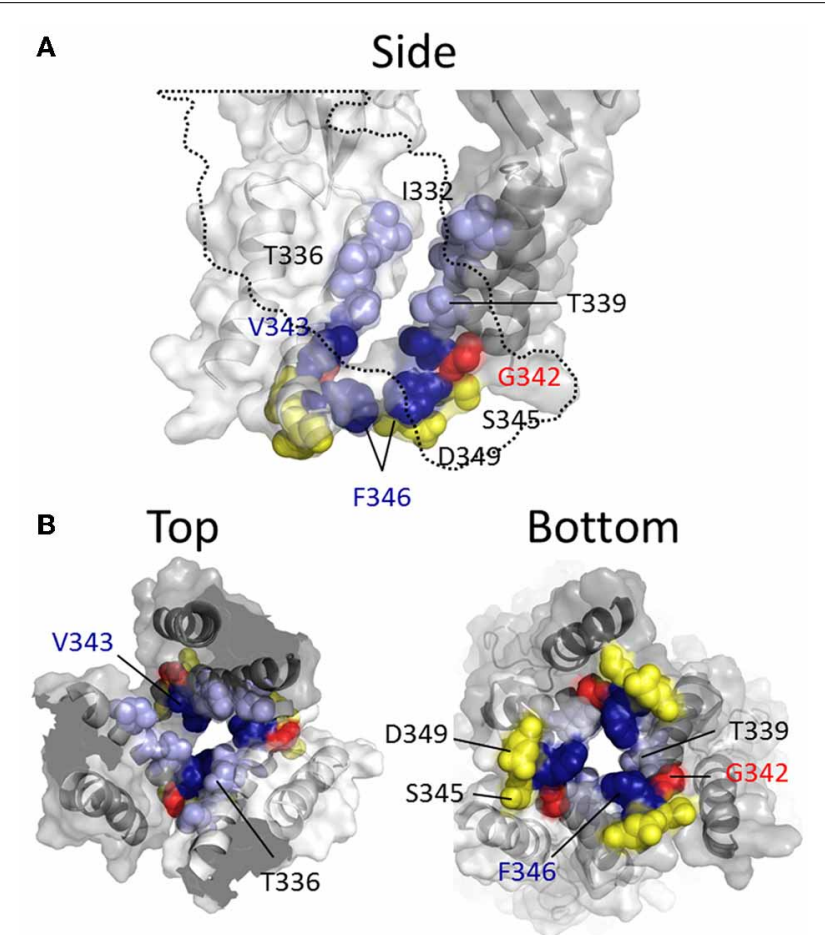

FIGURE 5 | Mapping P2X2R TM2 substituted cysteine side chains capable of coordinating $\mathrm{Cd}^{2+}$ in the open channel state. Side chains at which cysteine substitution renders the mutant receptor sensitive to current modification by $\mathrm{Cd}^{2+}$ applied in the presence of ATP are shown as ball models. (A) Side view of TM domains with third subunit omitted for clarity (dotted line). (B) TM domains viewed from extracellular (left panel) and intracellular perspectives (right panel). Color coordination is as follows: Light blue, mutant currents reversibly inhibited by $\mathrm{Cd}^{2+}$; Dark blue, mutant currents irreversibly inhibited by $\mathrm{Cd}^{2+}$; Yellow, mutant currents irreversibly modified due to $\mathrm{Cd}^{2+}$ coordination between introduced Cys side chain and native amino acid side chains; Red, mutant currents reversibly potentiated by $\mathrm{Cd}^{2+}$. as predicted by Li et al. (2010). For Val ${ }^{343}$, the distance between $\alpha$-carbons in the P2X2R homology models closes to $\sim 12 \AA$, and for Phe ${ }^{346}$ the distance closes to $\sim 14 \AA$ (see Figure 7, pink). This is still not quite optimal for $\mathrm{Cd}^{2+}$ bridge formation, but one must consider the limitations of homology modeling, potential inaccuracies in TM arrangement as represented by the open state crystal structure (Heymann et al., 2013), and the possibility that the P2X receptor can visit open state conformations in which these side chains come into closer proximity (Kwan et al., 2012).

The $\alpha$-carbons at positions $\mathrm{Ser}^{345}$ and $\mathrm{Asp}^{349}$ are positioned relatively distant from their intersubunit counterparts even in the open channel pore, at 21 and $19 \AA$, respectively (Figure 5). However, in the case of these mutants, additional experiments conducted by Li et al. and Kracun et al., respectively, showed that $\mathrm{Cd}^{2+}$ coordination here might occur removed from the central pore axis, and involve additional native side chains present in the transmembrane domains. Thus, $\mathrm{Cd}^{2+}$ block of D349C was abolished when the native $\mathrm{Cys}^{348}$ adjacent to $\mathrm{Asp}^{349}$ was mutated to threonine (Kracun et al., 2010) (see Figure 1), whereas $\mathrm{Cd}^{2+}$ block of S345C was abolished by substitution of the nearby $\mathrm{His}^{33}$ of TM1 with tyrosine (Li et al., 2010). The effects of $\mathrm{Cd}^{2+}$ at these mutants, then, is not due to direct, steric blockade of ion flux due to $\mathrm{Cd}^{2+}$ occupying the channel pore, but may be due to an effect on channel gating.

\section{Closed state specific SCAM hits}

Thiol-reactive agents have also been used to probe the accessibility of TM2 substituted cysteines specifically in the closed channel state of P2X2R. This involved exposure of mutants to thiol-reactive agents in the absence of ATP, and then comparing the amplitudes of subsequent ATP-gated currents to control currents evoked prior to MTS exposure. In early studies, two laboratories reported that currents through the following mutants were observed to be altered by prolonged exposure to $\mathrm{MTSEA}^{+}$ applied in the absence of ATP: I328C, N333C, L334C, L338C, T336C, T339C, L338C, G342C, S345C, and D349C (Rassendren et al., 1997; Egan et al., 1998) (Figure 6). However, Egan et al., observed that inclusion of free cysteine in the patch pipette solution, thereby sequestering intracellular $\mathrm{MTSEA}^{+}$, was found to prevent thiol-modification of currents evoked through the mutants, L334C, L338C, T339C, G342C, and S345C, suggesting that MTSEA ${ }^{+}$accesses these side chains from the cytosol by first passively diffusing through the lipid bilayer in the uncharged state (Rassendren et al., 1997; Egan et al., 1998). Consistent with this, a later study also conducted in P2XR cysteine mutants revealed that the rate of current modification by $\mathrm{Ag}^{+}$and $\mathrm{MTSET}^{+}$was markedly reduced in the closed channel state for the mutants T336C and T339C (Li et al., 2008). In contrast, I328C and I332C were as rapidly modified by $\mathrm{Ag}^{+}$and $\mathrm{MTSET}^{+}$in the closed as in the open state of the channel. I332C was also found to be accessible to $\mathrm{Cd}^{+}$modification in the closed channel state, as was the mutant T336C (Kracun et al., 2010) (Figure 6, green and blue). That I328C currents are modified is not surprising given their apparent location near to the lateral portals, which are wide in both the closed and open channel state. That positions $\mathrm{Leu}^{338}, \mathrm{Thr}^{339}$, Gly ${ }^{342}$, and $\mathrm{Ser}^{345}$ are accessible to intracellular MTS reagents is mostly consistent with the closed channel crystal 


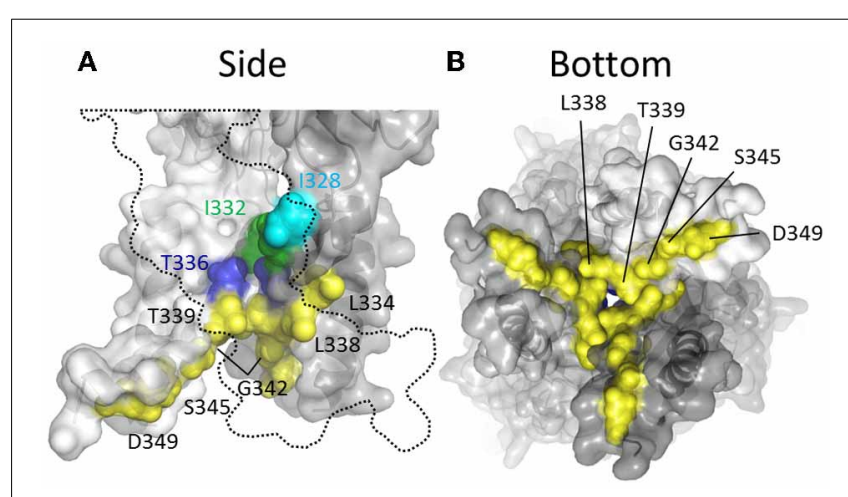

FIGURE 6 | Mapping P2X2R TM2 side-chains accessible to water-soluble thiol-reactive agents in the closed state using SCAM. (A) Side view of TM domains. Two subunits are shown with the third omitted for clarity (dotted outline). (B) TM domains viewed from the intracellular side of the membrane. The colored residues indicate positions at which substitution with cysteine produces a mutant that mediates currents sensitive to modification by thiol-reactive agents applied in the closed channel state. Color coordination is as follows: Cyan, mutant currents modified by external $\mathrm{MTSEA}^{+}$and $\mathrm{MTSET}^{+}$applied in the closed state; Green, mutant currents modified by external $\mathrm{Ag}^{+}, \mathrm{Cd}^{2+}$, and MTSET $^{+}$applied in the closed state; Blue, mutant currents modified by external $\mathrm{Cd}^{2+}$ applied in the closed state; Yellow, mutant currents modified by intracellular MTSEA ${ }^{+}$applied in the closed state.

structure, in which these positions can be seen to be exposed to the cytosol within the inverted cone opening out from the putative channel gate (Figure 6, yellow).

\section{LOCATION OF THE CHANNEL GATE}

SCAM studies conducted prior to the publication of the closed state crystal structure for the P2XR revealed divergent hypotheses on the exact position of the channel gate in members of the ion channel family. Egan et al. (1998) observed that only intracellular MTSEA ${ }^{+}$could access a Cys introduced at position Leu ${ }^{334}$ of $\mathrm{P} 2 \mathrm{X} 2 \mathrm{R}$ in the closed state, implying that this residue might form the intracellular extreme of the gate constriction. However, in the same study, Gly ${ }^{342}$ was found to be accessible by MTSEA ${ }^{+}$ from both sides of the membrane rendering a firm conclusion on gate position difficult. Rassendren et al. (1997) argued for a gate location between $\mathrm{Leu}^{338}$ and $\mathrm{Asp}^{349}$, finding that, in contrast to Egan et al. (1998) extracellular MTSEA ${ }^{+}$could access and modify $\mathrm{Leu}^{338}$ in the closed channel state.

In two later studies, Li et al. (2008) concluded that the closed state pore narrowed to an ion impermeable constriction within the stretch of amino acids between $\mathrm{Ile}^{332}$ and $\mathrm{Thr}^{339}$ ( $\mathrm{Li}$ et al., 2008; Kracun et al., 2010). Cysteines introduced here required progressively longer applications of $\mathrm{MTSET}^{+}$for functional modification of the channel. It was observed that $\mathrm{Ag}^{+}$and $\mathrm{Cd}^{2+}$ access to a Cys substituted for $\mathrm{Ile}^{332}$ was unaffected by whether the channel was opened or closed, but that Cys introduced at positions intracellular to $\mathrm{Thr}^{336}$ were almost completely inaccessible in the closed state, supporting the idea that the main barrier to small monovalent cations began in this region of the pore ( $\mathrm{Li}$ et al., 2008; Kracun et al., 2010). Looking to the crystal structures, according to the closed state homology model for P2X2R

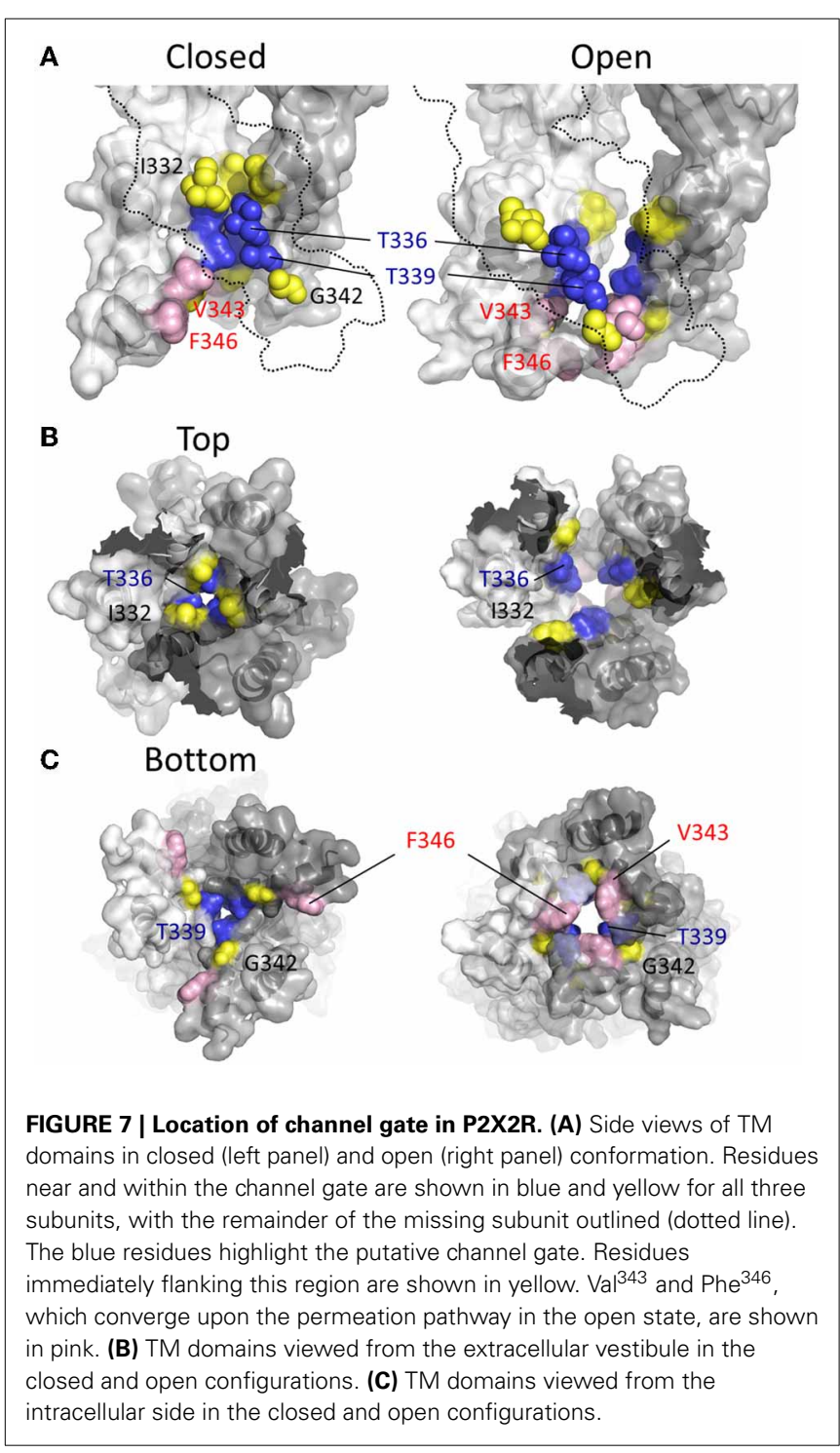

the barrier to ion permeation is formed by $\mathrm{Thr}^{336}$ and $\mathrm{Thr}^{339}$ (Figure 7, blue). This agrees with the predictions of Kracun et al. (2010) and Li et al. (2008) that the extracellular side of the gate occurs just below Ile ${ }^{332}$ (Figure 7, yellow) and is in accordance with SCAM studies investigating the effect of $\mathrm{Cd}^{2+}$ and $\mathrm{Ag}^{+}$ on mutants P2X2Rs containing Cys substitutions within TM2 (Kracun et al., 2010; Li et al., 2010).

\section{ION SELECTION AND PERMEATION}

P2XRs are commonly described as non-selective cation channels, being chiefly permeable to $\mathrm{Na}^{+}, \mathrm{K}^{+}$and $\mathrm{Ca}^{2+}$ under physiological conditions, although at least one family member has significant permeability to $\mathrm{Cl}^{-}$(North, 2002). Like other cation-permeable LGICs, at negative membrane potentials the ionic electrochemical gradients chiefly favor influx of $\mathrm{Na}^{2+}$ and $\mathrm{Ca}^{2+}$ through P2XRs, causing depolarization and an elevation in $\left[\mathrm{Ca}^{2+}\right]_{i}$. The depolarization is sufficient to initiate action potential propagation (Cook et al., 1997; Dowd et al., 1998; 
Kirkup et al., 1999; Rong and Burnstock, 2004) and the elevation in $\left[\mathrm{Ca}^{2+}\right]_{i}$ can affect a diverse array of $\mathrm{Ca}^{2+}$-dependent signaling processes, including synaptic transmission (Khakh and Henderson, 1998; Boehm, 1999; von Kugelgen et al., 1999; Khakh and Henderson, 2000), smooth muscle contraction (Smith and Burnstock, 2004), and cell survival (Adinolfi et al., 2005).

This review will confine itself to a very brief and simplified general introduction to the study of ion selectivity and flux through ion channels, before reviewing the current understanding of these matters with respect to P2XRs. A more thorough discussion of the general mechanisms underlying ion selectivity and flux ion channels can be obtained from other sources (Eisenman and Horn, 1983; Eisenman and Dani, 1987; Hille, 2001). The reader is also directed to reviews covering ion selectivity and flux through specific ion channels, such as the voltage-gated $\mathrm{K}^{+}$(Roux, 2005), $\mathrm{Na}^{+}$(Catterall, 2012), and $\mathrm{Ca}^{2+}$ (Sather and McCleskey, 2003) channels, and the ligand-gated Cys-loop (Sine et al., 2010), and ionotropic glutamate receptors (Traynelis et al., 2010).

The study of ion permeability and flux has a rich and prestigious history (Hille, 2001 and see Catterall et al., 2012), and the topic can be approached using a number of experimental techniques. The most common approaches involve the estimation of the "relative permeability" of ions, either from determination of current reversal potentials or from the comparison of single channel conductances in solutions of varying ionic composition. Relative permeabilities are usually reported for an ion, $\mathrm{X}$, with respect to $\mathrm{Na}^{+}, \mathrm{P}_{\mathrm{X}} / \mathrm{P}_{\mathrm{Na}}$, or $\mathrm{Cs}^{+}, \mathrm{P}_{\mathrm{X}} / \mathrm{P}_{\mathrm{Cs}}$, and are calculated from experimental reversal potential and/or single channel conductance data using the Goldman-Hodgkin-Katz (GHK) voltage and current equations, respectively (Hille, 2001). Despite the fact that ion permeation through most, if not all, ion channels violates the assumptions of independence implicit to the GHK model (that permeating ions neither interact with the walls of the channel pore nor with other ions in the permeation pathway), these methods have nevertheless provided a good approximation of ion permeability for a number of cation non-selective LGICs. Nevertheless, in the case of assessing relative $\mathrm{Ca}^{2+}$ permeability, an alternative model-independent method is becoming more commonly used, the "fractional $\mathrm{Ca}^{2+}$ current" or "dye overload" method developed by Neher (1995) and Rogers and Dani (1995). This involves performing whole cell patch clamp fluorimetry with a pipette containing a saturating concentration of the $\mathrm{Ca}^{2+}$ dye, fura-2, and measuring both ionic current and $\mathrm{Ca}^{2+}$ influx simultaneously. From this, direct determination of the contribution of $\mathrm{Ca}^{2+}$ to the total inward current is obtained in the presence of physiological concentrations of extracellular $\mathrm{Ca}^{2+}$. By contrast, to determine $\mathrm{P}_{\mathrm{Ca}} / \mathrm{P}_{\mathrm{Cs}}$ using the reversal potential method commonly requires the use of non-physiological ionic solutions, and only allows permeability to be determined for a single membrane potential (the $E_{\mathrm{Rev}}$ ). This technique has proved particularly useful, then, for estimating $\mathrm{Ca}^{2+}$ flux in a physiologically normal ionic environment and at a range of membrane potentials most likely encountered by an animal cell in vivo (Burnashev, 1998; Jatzke et al., 2002; Egan and Khakh, 2004; Fucile, 2004; Samways et al., 2008b).

The entry of an ion into a channel pore and subsequent conductance across the biological membrane partition is influenced by a number of ion channel pore properties (see Hille, 2001). First, the maximum diameter of the channel pore will provide a steric size limit on permeating ions, allowing selection by "molecular sieving". Second, the electrostatic environment near the openings of the pore can produce local surface potentials that contribute to selectivity by attracting and repelling ions based on charge. Lastly, the presence of charged and polar side chains, or backbone carbonyls, oriented toward the axis of narrow portions of the ion permeating pathway can directly interact with the permeating ions, assisting with dehydration, if necessary, for the ion to pass through completely.

\section{UPPER PORE SIZE LIMIT FOR P2XRS}

An early rough estimate based on single channel cation conductance predicted the $\mathrm{P} 2 \mathrm{X} 2 \mathrm{R}$ pore diameter to be $\sim 20 \AA$ at its narrowest point (Ding and Sachs, 1999a), much larger than the $\sim 7 \AA$ predicted by the crystal structure of the open P2X4R (Hattori and Gouaux, 2012). Functional studies of cation permeability and uptake of fluorescent cationic dyes suggest that the pore diameter of $\mathrm{P} 2 \mathrm{XRs}$ can accommodate cation species as large as the cationic dye YO-PRO1 and the large thiol-reactive agent $\mathrm{MTS}-\mathrm{TPAE}^{+}$, predicting a maximum pore diameter closer to $12-14 \AA$ (Khakh et al., 1999a; Li et al., 2010; Browne et al., 2013). An explanation for the discrepancy is that the open pore has a considerable degree of flexibility, a notion supported by the phenomenon of "pore dilation" (see below), which is proposed to allow certain members of the P2XR family to increase their permeability to larger cation species (Khakh et al., 1999a; Virginio et al., 1999a). For comparison, the pore diameters of other LGICs are as follows: the nAChR, $\sim 8 \AA$ (Albuquerque et al.,

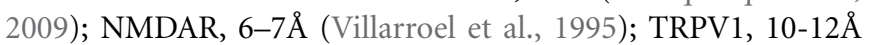
(Chung et al., 2008); and ASIC1, $\sim 4 \AA$ (Carattino and Della Vecchia, 2012).

\section{CATION vs. ANION SELECTION}

P2XRs are broadly described as non-selective cation channels that favor the conduction of positively charged ions, such as $\mathrm{Na}^{+}$, $\mathrm{K}^{+}$, and $\mathrm{Ca}^{2+}$, vs. negatively charged ions such as $\mathrm{Cl}^{-}$(North, 2002). The family members P2X1R, P2X2R, P2X4R, and P2X7R all exhibit a $\mathrm{Cl}^{-}$permeability relative to monovalent cations of less than 0.1 (Virginio et al., 1999b; Samways and Egan, 2007; Browne et al., 2013) (Table 1). Nevertheless, ATP-gated currents with significant $\mathrm{Cl}^{-}$permeability have been recorded previously in native cells (Thomas and Hume, 1990), and some recombinant P2X5R have a $\mathrm{P}_{\mathrm{Cl}} / \mathrm{P}_{\mathrm{Na}}$ of 0.5-0.7 (Ruppelt et al., 2001; Bo et al., 2003; Samways and Egan, 2007). Exactly how the predominantly cation-selective P2XRs discriminate between cations and anions has yet to be adequately determined. Resolution of the P2X4R crystal structure revealed that the extracellular vestibule carries a net negative surface charge, primarily due to the presence of Glu ${ }^{56}$ and $\mathrm{Asp}^{58}$ (human P2X4R numbering), and free energy calculations conducted using the zfP2X4R closed structure as a model support the view that $\mathrm{Na}^{+}$and $\mathrm{Ca}^{2+}$ entry into this domain is favored relative to $\mathrm{Cl}^{-}$(Kawate et al., 2009, 2011). However, a number of observations are inconsistent with this hypothesis. Firstly, there is little correlation between the conservation of charge at positions analogous to $\mathrm{Glu}^{56}$ and $\mathrm{Asp}^{58}$ and the 
Table 1 | Relative permeability and fractional $\mathrm{Ca}^{2+}$ current (Pf\%) data for recombinant homomeric P2XRs.

\begin{tabular}{|c|c|c|c|c|}
\hline P2XR & $\begin{array}{c}\mathrm{P}_{\mathrm{Cl}} / \mathrm{P}_{\mathrm{X}_{+}} \\
\text {Derived from } E_{\text {rev }}\end{array}$ & $\begin{array}{c}\mathrm{P}_{\mathrm{Ca}_{\mathrm{a}}} / \mathrm{P}_{\mathrm{X}_{+}} \\
\text {Derived from } E_{\mathrm{rev}}\end{array}$ & $\begin{array}{c}\mathrm{Ca}^{2+} \text { flux } \\
\text { Pf\% }\end{array}$ & References \\
\hline $\mathrm{P} 2 \mathrm{X} 1 \mathrm{R}$ & 0.09 & $3.6-3.9$ & 12 & Evans et al., 1996; Egan and Khakh, 2004; Samways and Egan, 2007 \\
\hline $\mathrm{P} 2 \mathrm{X} 3 \mathrm{R}$ & n.d. & 1.2 & $3-4.8$ & Egan and Khakh, 2004; Samways and Egan, 2007; Ma et al., 2012 \\
\hline P2X7R & $<0.1$ & 35 & 4.6 & $\begin{array}{l}\text { Bretschneider et al., 1995; Virginio et al., 1999b; Egan and Khakh, 2004; Browne } \\
\text { et al., } 2013\end{array}$ \\
\hline
\end{tabular}

$X^{+}$represent either $\mathrm{Na}^{+}$or $\mathrm{Cs}^{+}$depending on experimental method used.

cation vs. anion selectivity exhibited by P2XRs. Thus, whereas the strongly cation selective channel P2X1R has Ser at both of these positions, and no neighboring acidic side chains to compensate for the loss of charge, P2X5R has an Asp at both positions but exhibits a much weaker cation vs. anion selectivity (see Figure 1). Secondly, in trying to elucidate the structural basis of $\mathrm{Cl}^{-}$permeation in P2X5R, Bo et al. (2003) observed that neutralizing the positive charge at position Lys $^{52}$, which is occupied by a neutral Gln in P2X2R and an acidic Glu or Asp in P2X1R, P2X3R, P2X4R, and $\mathrm{P} 2 \mathrm{X} 7 \mathrm{R}$, had no effect on $\mathrm{P}_{\mathrm{Cl}} / \mathrm{P}_{\mathrm{Na}}$. Further, the complimenting mutation in $\mathrm{P} 2 \mathrm{X} 2 \mathrm{R}$, substitution of Lys for $\mathrm{Gln}^{52}$, had no effect on this channel's $\mathrm{P}_{\mathrm{Cl}} / \mathrm{P}_{\mathrm{Na}}$. Although these results are curious in light of evidence that this position regulates $\mathrm{Ca}^{2+}$ selection and flux relative to $\mathrm{Na}^{+}$in P2XRs (Samways and Egan, 2007 and see below), it seems to imply that charge selection is not a major function of the lateral portals/extracellular vestibule of the P2XR structure. A third observation that challenges the view that charge selection might happen extracellular to the transmembrane conducting pathway is that, in SCAM studies of P2X4R, negatively charged MTSES $^{-}$was found to access and modify substituted cysteines introduced into the extracellular vestibule at positions $\mathrm{Glu}^{56}$, $\mathrm{Thr}^{57}, \mathrm{Asp}^{58}$, and $\mathrm{Ser}^{59}$ of P2X4R, and as deep into the transmembrane pore as $\mathrm{Thr}^{336}$ and $\mathrm{Ser}^{341}$ of $\mathrm{P} 2 \mathrm{X} 2 \mathrm{R}$ and P2X4R, respectively (Rassendren et al., 1997; Samways et al., 2011). The modification rates were not that dissimilar to those observed for the positively charged but similarly sized $\mathrm{MTSET}^{+}$, suggesting that any charge selection barrier within the typical P2XR is likely to be within, or intracellular to, the channel gate. Interestingly, charge selection was observed in the central vestibule, above the extracellular vestibule, where $\mathrm{MTSET}^{+}$, but not $\mathrm{MTSES}^{-}$, was found to access and modify cysteines introduced at positions $\mathrm{Ser}^{62}$ and $\mathrm{Asn}^{97}$ of P2X4R (Samways et al., 2011). Nevertheless, the proximity of the central vestibule is clearly not preventing MTSES $^{-}$from intruding deep into the transmembrane pore, likely because the pore opening is too far removed from the influence of the central vestibule's surface potential.

It seems more plausible, then, that cation vs. anion selection occurs further along the ion conducting pathway, perhaps deep within the transmembrane spanning pore as has been suggested for the Cys-loop family of ion channels (Sine et al., 2010). Although this has not been investigated systematically as yet, it has been shown that substitution of Thr ${ }^{339}$ of P2X2R for Lys, thereby creating a symmetrical lining of positive charge deep in the open channel pore, renders the channel non-selective for $\mathrm{Na}^{+}$vs. $\mathrm{Cl}^{-}$ (Browne et al., 2011). Further, substitution of Arg at position $\mathrm{Thr}^{339}$ conferred a reversal of selectivity, with this mutant displaying a modest $\mathrm{P}_{\mathrm{Cl}} / \mathrm{P}_{\mathrm{Na}}$ of $\sim 2$. However, although $\mathrm{Thr}^{339}$ has been previously implicated in selection between mono- and divalent cations (Migita et al., 2001; Egan and Khakh, 2004), it is very weakly conserved position among P2XR family members, being occupied by Gly in P2X1R and Ala in P2X4R for example. It is difficult, then, to draw general conclusions about its role in selection and permeation. In P2X7R, substitution of residues intracellular to the gating region also affected cation vs. anion selection, with substitution of Lys at positions $\mathrm{Thr}^{348}\left(\mathrm{Ser}^{345}, \mathrm{P} 2 \mathrm{X} 2 \mathrm{R}\right)$ and Asp ${ }^{352}$ $\left(\mathrm{Asp}^{349}, \mathrm{P} 2 \mathrm{X} 2 \mathrm{R}\right.$ ) significantly enhancing $\mathrm{P}_{\mathrm{Cl}} / \mathrm{P}_{\mathrm{Na}}$ (Browne et al., 2013), but again it is not clear whether these positions play an important role in charge discrimination, particularly for extracellular cations. The lack of concrete data regarding the structural underpinning of cation vs. anion selectivity is a significant deficit in our understanding of P2X function and one that would be timely to address.

\section{DISCRIMINATION BETWEEN MONOVALENT CATIONS}

P2XRs are considered "non-selective" cation channels in large part because they do not discriminate well between small monovalent alkali ion species. Studies using the whole cell reversal potential method reported that neither P2X1R nor P2X2R could substantially discriminate between $\mathrm{Na}^{+}, \mathrm{K}^{+}, \mathrm{Cs}^{+}$, or $\mathrm{Rb}^{+}$(Evans, 1996). These data are largely consistent with relative permeability data obtained from single channel measurements of monovalent cation conductance, where $\mathrm{K}^{+}, \mathrm{Rb}^{+}$, and $\mathrm{Cs}^{+}$were more-or-less equally permeable, and $\mathrm{Na}^{+}$only marginally less so (Ding and Sachs, 1999a). Interestingly, $\mathrm{Li}^{+}$exhibited a significantly higher permeability relative to $\mathrm{Na}^{+}, \mathrm{K}^{+}, \mathrm{Cs}^{+}$, and $\mathrm{Rb}^{+}$as assessed from whole cell reversal potentials (Migita et al., 2001), but a lower relative permeability as assessed from single channel conductance studies (Ding and Sachs, 1999a). This is consistent with the presence of an intrapore binding site with higher selectivity for $\mathrm{Li}^{+}$relative to the other alkali metal ions, with the stronger interaction slowing $\mathrm{Li}^{+}$conductance through the channel (Hille, 2001). There has been some difficulty in resolving the cation conductances for all the recombinant P2XRs due to the channels exhibiting very short, flickery openings. Estimates 
of $\mathrm{Na}^{+}$conductance at membrane potentials between -100 and $-150 \mathrm{mV}$ are available for P2X1R [ 12 pS; (Evans, 1996)], P2X2R [21-35 pS (Evans, 1996; Ding and Sachs, 1999b)], P2X4R [9-18 pS (Evans, 1996; Priel and Silberberg, 2004; Samways et al., 2011)] and P2X7R [9-13 pS (Riedel et al., 2007)]. For comparison, under similar conditions the conductances of other non-selective cation channels including the nicotinic acetylcholine receptors, glutmate-gated NMDA receptors, and capsaicin-sensitive TRPV1 receptors are 25-50 pS (Mathie et al., 1991), 20-40 pS (Stern et al., 1992), and 50-60 pS (Premkumar et al., 2002; Samways and Egan, 2011), respectively.

\section{$\mathrm{CA}^{2+}$ SELECTIVITY AND FLUX}

All of the P2X receptor subunits confer $\mathrm{Ca}^{2+}$ permeability, with the selectivity of the functional channel depending on the constituent subunits (Egan and Khakh, 2004). The homomeric $\mathrm{P} 2 \mathrm{X} 1 \mathrm{R}$ and $\mathrm{P} 2 \mathrm{X} 4 \mathrm{R}$ receptors have the highest relative $\mathrm{Ca}^{2+}$ permeability, with reversal potential-derived $\mathrm{P}_{\mathrm{Ca}} / \mathrm{P}_{\mathrm{Cs}}$ values of $\sim 4-5$ (Evans et al., 1996; Garcia-Guzman et al., 1997; Samways and Egan, 2007) (Table 1). The use of the superior fluorimetric flux method (Neher, 1995) confirmed the ability for these receptors to conduct an appreciable $\mathrm{Ca}^{2+}$ influx, showing that $\mathrm{Ca}^{2+}$ carries $12 \%$ and $16 \%$ of the total inward currents through P2X1R and $\mathrm{P} 2 \mathrm{X} 4 \mathrm{R}$, respectively, at $-60 \mathrm{mV}$ in the presence of $2 \mathrm{mM}$ extracellular $\mathrm{Ca}^{2+}$ (Egan and Khakh, 2004; Samways and Egan, 2007) (Table 1). P2X3R has the lowest recorded relative $\mathrm{Ca}^{2+}$ permeability of the family, with a reversal potential-determined $\mathrm{P}_{\mathrm{Ca}} / \mathrm{P}_{\mathrm{Cs}}$ of 1.6 (Virginio et al., 1998) and a fractional $\mathrm{Ca}^{2+}$ current of 3$5 \%$. This method also allowed a more accurate estimate of $\mathrm{Ca}^{2+}$ flux through recombinant $\mathrm{P} 2 \mathrm{X} 7$ receptor, which are inhibited by the high external $\mathrm{Ca}^{2+}$ concentrations required to obtain reversal potential-based measurements of $\mathrm{P}_{\mathrm{Ca}} / \mathrm{P}_{\mathrm{Na}}$. Indeed, a previous estimate of $\mathrm{P} 2 \mathrm{X} 7$ relative $\mathrm{Ca}^{2+}$ permeability from reversal potentials reported a $\mathrm{P}_{\mathrm{Ca}} / \mathrm{P}_{\mathrm{Na}}$ of 35 (Bretschneider et al., 1995), which is far in excess of what is predicted for a channel with a Pf\% reading of $\sim 5 \%$ (Egan and Khakh, 2004) (Table 1).

As expected, the variability in relative $\mathrm{Ca}^{2+}$ permeability exhibited between P2XR subunits correlates with a variability in the $\mathrm{Ca}^{2+}$ permeabilities of ATP-gated currents in native tissues. For example, in smooth muscle cells, reversal potential measurements allowed an estimation of $\mathrm{P}_{\mathrm{Ca}} / \mathrm{P}_{\mathrm{Na}}=3$ for P2XRmediated currents, which is in agreement with the highly $\mathrm{Ca}^{2+}$ permeable $\mathrm{P} 2 \mathrm{X} 1 \mathrm{R}$ being a predominant subtype in this tissue (Benham et al., 1991). Reversal potential experiments conducted in ATP-sensitive neurons have yielded $\mathrm{Ca}^{2+}$ permeability values of $\mathrm{P}_{\mathrm{Ca}} / \mathrm{P}_{\mathrm{Cs}}=\sim 1.5$ for nodose ganglion neurons (Virginio et al., 1998) and $\mathrm{P}_{\mathrm{Ca}} / \mathrm{P}_{\mathrm{Cs}}=\sim 2$ for retinal ganglion neurons (Taschenberger et al., 1999), both cell types of which likely express homo- and heteromeric P2X2R and P2X3R. In addition, early $\mathrm{Pf} \%$ experiments conducted in sympathetic neurons reported that, at $-60 \mathrm{mV}$ in the presence of $2.5 \mathrm{mM}$ extracellular $\mathrm{Ca}^{2+}$, approximately $7 \%$ of the total ATP-gated current was carried by $\mathrm{Ca}^{2+}$ (Rogers and Dani, 1995). In activated, P2X4R expressing mammalian microglial cells, ATP-gated currents exhibited a Pf\% value of $17 \%$ (Toulme et al., 2010), comparable to the $16 \%$ calculated for the recombinant mammalian receptor (Egan and Khakh, 2004; Samways and Egan, 2007).
In contrast to our relative lack of understanding with regard to how P2XRs discriminate between cations and anions, we have at least some idea of which amino acid side chains are important in regulating $\mathrm{Ca}^{2+}$ selectivity and flux through this family of ion channels. Studies using both the reversal potential and Pf\% methods initially revealed an important role of polar side chains within TM2 in regulating $\mathrm{Ca}^{2+}$ selection in P2X2R (Migita et al., 2001; Egan and Khakh, 2004). Specifically, it was found that substitution of the polar residues $\mathrm{Thr}^{336}$, $\mathrm{Thr}^{339}$, and $\mathrm{Ser}^{340}$ with hydrophobic residues of similar size almost abolished the selectivity between $\mathrm{Ca}^{2+}$ and $\mathrm{Na}^{+}$(Migita et al., 2001) and substantially reduced the Pf\% (Egan and Khakh, 2004). The homology model of $\mathrm{P} 2 \mathrm{X} 2 \mathrm{R}$ is consistent with this, showing that the three residues are located in the narrow part of channel pore and that two of them, $\mathrm{Thr}^{336}$ and $\mathrm{Thr}^{339}$, are oriented directly into the permeation pathway in the open channel state (see Figures 4, 7). Indeed, increasing the side chain volume at these positions via substitution with Tyr actually formed a barrier to $\mathrm{Ca}^{2+}$ permeation, causing the reversal potential-based $\mathrm{P}_{\mathrm{Ca}} / \mathrm{P}_{\mathrm{Cs}}$ to be $\sim 0.3$ for the mutant T339Y, and $<0.1$ for S340Y (Migita et al., 2001), and the respective $\mathrm{Pf} \%$ s recorded as $\sim 1$ and $0.2 \%$ (Egan and Khakh, 2004) (T336Y was nonfunctional). From this, it would be tempting to speculate that the hydroxyl groups on these side chains might act as surrogate water-like ligands, assisting in the dehydration of permeating $\mathrm{Ca}^{2+}$ ions. For $\mathrm{Thr}^{336}$, this hypothesis has merit, as a hydroxyl-bearing Ser or Thr side chain resides at this relative position in all the $\mathrm{P} 2 \mathrm{X}$ receptors with the sole exception of P2X3R (where it is occupied by Ala), P2X3R having the lowest $\mathrm{Ca}^{2+}$ permeability. The hydroxyl group of $\mathrm{Thr}^{339}$, on the other hand, is only retained in the moderately $\mathrm{Ca}^{2+}$ permeable P2X2R (Thr) and P2X7R (Ser), but is absent in the highly $\mathrm{Ca}^{2+}$ permeable P2X1R (Gly) and P2X4R (Ala). The properties of the side chain at position $\mathrm{Ser}^{340}$ in $\mathrm{P} 2 \mathrm{X} 2 \mathrm{R}$ are very poorly conserved, with this position most commonly being occupied by a hydrophobic residue, such as Leu (P2X4, P2X5), Ile (P2X1), Tyr (P2X7), or Trp (P2X6).

Only one negatively charged side chain is present within the actual TM domains of P2XRs, and this is a conserved Asp on the intracellular extreme of TM2 at the position analogous to Asp ${ }^{349}$ of P2X2R (Figure 4) and Asp ${ }^{354}$ (P2X4R). It is highly conserved throughout the vertebrate $\mathrm{P} 2 \mathrm{XRs}$, but substitution of this residue had no effect on either the reversal potential-derived $\mathrm{P}_{\mathrm{Ca}} / \mathrm{P}_{\mathrm{Cs}}$ or the Pf\% of P2X2R (Migita et al., 2001; Egan and Khakh, 2004). However, Fountain et al. (Fountain et al., 2008) observed that a $\mathrm{P} 2 \mathrm{XR}$ isoform found in green algae, which possesses an Asn at this position, exhibited a $50 \%$ increase in the reversal-potentialderived $\mathrm{P}_{\mathrm{Ca}} / \mathrm{P}_{\mathrm{Na}}$ upon substitution for Asp.

Even if a hydroxyl-bearing side chain at the position analogous to $\mathrm{Thr}^{336}$ of $\mathrm{P} 2 \mathrm{X} 2 \mathrm{R}$ plays a role in $\mathrm{Ca}^{2+}$ selectivity, it cannot easily explain the diversity in relative $\mathrm{Ca}^{2+}$ permeabilities between the different P2XRs. Why do P2X1R and P2X4R have such a high $\mathrm{Ca}^{2+}$ permeability? Inspection of the primary amino acid sequences reveals that at positions located just extracellular to TM1 and TM2, analogous to positions Glu ${ }^{51}$ and $\mathrm{Asp}^{331}$ of $\mathrm{P} 2 \mathrm{X} 4$, some P2XRs possess fixed negative charge. Samways and Egan (2007), hypothesized that this formal charge might serve to attract divalent cations, and indeed neutralizing both charges 
significantly attenuated $\mathrm{Ca}^{2+}$ selectivity and relative conductance in $\mathrm{P} 2 \mathrm{X} 1 \mathrm{R}$ and $\mathrm{P} 2 \mathrm{X} 4 \mathrm{R}$ receptors. Complimentary mutations that substituted these charges into P2X2R, the wild type of which has Gln and Ser at these positions, significantly increased the Pf\% of this receptor. Further, these acidic side chains could be titrated by reducing extracellular $\mathrm{pH}$, subsequently reducing $\mathrm{Pf} \%$ for $\mathrm{P} 2 \mathrm{X} 1 \mathrm{R}$ and for the P2X2R-Q52E/S326D mutant.

$\mathrm{P} 2 \mathrm{X} 3 \mathrm{R}$ retains a Glu at the position analogous to $\mathrm{Glu}^{51}$ in $\mathrm{P} 2 \mathrm{X} 4 \mathrm{R}$ and possesses an Asn at Asp ${ }^{331}$. Interestingly, only one of the side chains needed be present for enhanced $\mathrm{Ca}^{2+}$ permeability in $\mathrm{P} 2 \mathrm{X} 1 \mathrm{R}, \mathrm{P} 2 \mathrm{X} 2 \mathrm{R}$, and $\mathrm{P} 2 \mathrm{X} 4 \mathrm{R}$ receptors, and yet $\mathrm{P} 2 \mathrm{X} 3 \mathrm{R}$ receptors have the lowest $\mathrm{Ca}^{2+}$ permeability of the family despite retaining the Glu analogous to Glu ${ }^{51}$ in P2X4R. However, here the Glu is closely flanked by the positive charge of a neighboring His (as well as that of the highly conserved Lys on the other side). In addition, the lack of a hydroxyl-bearing residue at the position analogous to $\mathrm{Thr}^{336}$ of P2X2R might also impair $\mathrm{Ca}^{2+}$ permeability in P2X3R. Nevertheless, substitution of the neighboring His residue with Tyr was observed to significantly elevate $\mathrm{Ca}^{2+}$ permeability (Samways and Egan, 2007).

Glu $^{51}$ and $\mathrm{Asp}^{331}$ are now known to line the lateral portals of $\mathrm{P} 2 \mathrm{X} 4 \mathrm{R}$, and it is tempting to speculate that the presence of fixed negative charge here could present a sufficient surface potential to concentrate the activity of cations, favoring the charge dense $\mathrm{Ca}^{2+}$ over $\mathrm{Na}^{+}$(Figure 8). However, as compelling as these data are, there are a few caveats to drawing general conclusions from them and applying them to the P2XR family as a whole. First, P2X7R has fixed charge at both of these positions, but the $\mathrm{Ca}^{2+}$ permeability is not quite as high as P2X1R and P2X4R (Figure 1 and Table 1). Second, P2X5R has a Lys at this position, and although this has previously been ruled out as a determinant of cation vs. anion discrimination, it seems unusual that P2X5R would maintain a $\mathrm{Ca}^{2+}$ permeability not far removed from that of $\mathrm{P} 2 \mathrm{X} 2 \mathrm{R}$ (Egan and Khakh, 2004) (Table 1). Third, and related to the second caveat, is the question of why lateral portal residues are sufficient to assist in discrimination between mono- and divalent

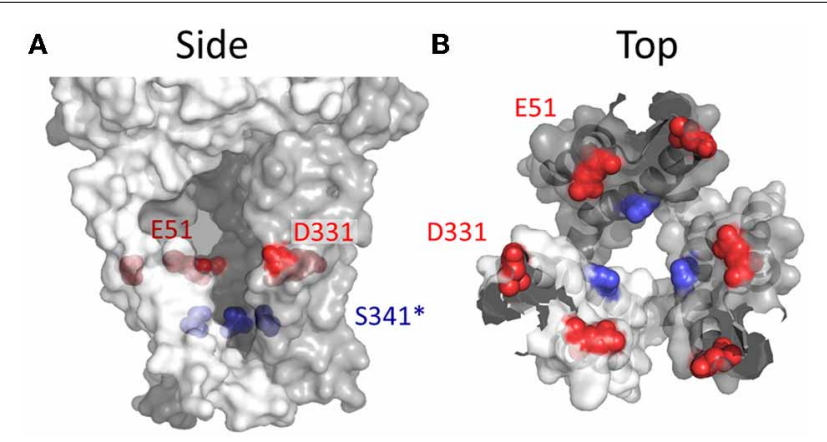

FIGURE 8 | Side chains affecting $\mathrm{Ca}^{2+}$ selection and flux in P2X4R.

(A) Side view of open state P2X4R homology model depicting residues known to regulate ion permeability. (B) P2X4R viewed from the extracellular vestibule looking intracellularly in the open configuration. Acidic side chain positions implicated in the regulation of $\mathrm{Ca}^{2+}$ permeation, $\mathrm{Glu}^{51}$ and $\mathrm{Asp}^{331}$ are shown in red. The position highlighted in blue is $\mathrm{Ser}^{341}$, a conserved hydroxyl bearing side chain predicted to regulate $\mathrm{Ca}^{2+}$ permeability based on data for the analogous position, $\mathrm{Thr}^{336}$, in $\mathrm{P} 2 \mathrm{X} 2 \mathrm{R}$. cations, but not sufficient to strongly influence discrimination between anions and cations.

It might be the case that, unlike the selectivity filters of other ion channels (Sather and McCleskey, 2003; Roux, 2005; Sine et al., 2010; Traynelis et al., 2010; Catterall, 2012), P2X receptors lack a single, discreet structural locus for ion selectivity. That instead, selectivity and conductance are regulated more diffusely, and involves multiple parts of the permeation pathway. Further experiments are required to test this hypothesis. A last interesting point to make about the relative $\mathrm{Ca}^{2+}$ permeability of $\mathrm{P} 2 \mathrm{XRs}$ is that it is sensitive to tuning via allosteric modulation. This was first shown for $\mathrm{P} 2 \mathrm{X} 1$, where reducing the extracellular $\mathrm{pH}$ was shown to attenuate $\mathrm{Pf} \%$, likely as a result of charge shielding of the acidic side chains that we know confer the higher $\mathrm{Ca}^{2+}$ permeability in P2X1R and P2X4R (Samways and Egan, 2007). More recently, it was shown that the drug ivermectin, previously known to enhance the open probability of P2X4Rs in the presence of ATP (Khakh et al., 1999b; Priel and Silberberg, 2004), has the additional effect of reducing the Pf\% of this receptor (Samways et al., 2012). Thus, far from being fixed properties of P2XRs, ion selection and conductance by these channels appears to be flexible and potentially amenable to fine tuning. In the last part of this review we will discuss a particularly unusual example of this flexibility with regard to the phenomenon described as "pore dilation".

\section{PORE DILATION}

A curious property of P2XRs was hinted at by early studies conducted on leukocytes, where it was revealed that prolonged exposure to ATP had the effect of permeabilizing the membrane to much larger ionic species than those usually conducted by LGICs, including 2-Amino-2-hydroxymethyl-propane-1,3-diol (TRIS), $\mathrm{N}$-methyl-D-glucamine $\left(\mathrm{NMDG}^{+}\right)$(Nuttle and Dubyak, 1994), and the cationic dye ethidium (Tatham et al., 1988; Wiley et al., 1993). In some mast cells and macrophages it was even observed that sustained ATP exposure promoted the uptake or leakage of large anionic dyes, including the $\mathrm{Ca}^{2+}$-sensor Fura-2 and Lucifer yellow (Steinberg et al., 1987; Yan et al., 2008). It was subsequently revealed that the purinergic receptor being acted upon by ATP in these cells was largely P2X7 (Surprenant et al., 1996). Since this discovery, sustained ATP activation of two other members of the family, P2X2R and P2X4R, has been shown to produce a similar biphasic effect on membrane permeability, causing a progressive change from a primarily $\mathrm{Na}^{+}, \mathrm{K}^{+}, \mathrm{Ca}^{2+}$ conducting current $\left(\mathrm{I}_{1}\right)$ to one that conducts passage of larger cations such as $\mathrm{NMDG}^{+}$and the propidium dye, YO-PRO1 $\left(\mathrm{I}_{2}\right)$ (Khakh et al., 1999a; Virginio et al., 1999a). A fact even more curious, but one that will not be discussed further in this review, is that two members of the structurally unrelated TRP family of ion channels, TRPV1 and TRPA1, has been observed to exhibit a strikingly similar form of dynamic permeability (Chung et al., 2008; Banke et al., 2010), hinting at a broader significance of this ion channel phenomenon.

Three basic hypotheses have been put forward with regard to the mechanism by which this time-dependent change in permeability to large ionic species occurs. The first posits that the phenomenon represents an intrinsic gating property of the functional P2XR channel, and that sustained ATP exposure causes the 
channel pore to literally widen as the commonly used term "pore dilation" describes, thereby mediating the progressive increase in permeability to large ionic species (Khakh and Lester, 1999; Khakh et al., 1999a; Virginio et al., 1999a). The switch from $\mathrm{I}_{1}$ to $\mathrm{I}_{2}$ might be spontaneous or regulated by second messengermediated modification of the channel protein (e.g., phosphorylation/dephosphorylation). The second hypothesis proposes that an agonist-dependent redistribution and oligomerization of P2XRs leads to the formation of macropores. These could potentially arise from the fusion of two or more trimeric P2XRs and an enlargement of the main functional channel pore, or as a result of a separate but larger pore formed between aggregating trimeric assemblies (Khakh and Egan, 2005; Khakh et al., 1999a). The third proposes that the permeability to large cations is mediated by a structurally separate transport pathway stimulated downstream of P2XR activation (Virginio et al., 1999a). The second hypothesis has been largely ruled out by a study utilizing total internal reflection fluorescence (TIRF) imaging to monitor the lateral movement of $\mathrm{P} 2 \mathrm{X} 2 \mathrm{R}$ within the plasma membrane during ATP stimulation, which found no compelling evidence of the redistribution and clustering that would be expected if these channels were oligomerizing into a higher stoichiometric pore structure (Khakh and Egan, 2005). Which of the two remaining hypotheses holds true has been more difficult to determine, with evidence for and against both mechanisms, and the possibility remaining that the observed change in membrane permeability during sustained ATP exposure may involve both intrinsic "pore dilation" and recruitment of secondary transport pathways, and that the contribution of these two mechanisms may differ depending on cell type (for review, see North, 2002; Pelegrin, 2011).

\section{Large ion permeation through the P2XR pore: $I_{1}$ to $I_{2}$ transition}

There is a substantial body of evidence that the intrinsic pores of P2X2R, P2X4R, and P2X7R receptors can potentially accommodate large cations, including fluorescent dyes. In addition to SCAM studies showing that large MTS reagents like MTS-TPAE and even Texas Red-MTSEA can gain access to side chains deep within the permeation pathway (Li et al., 2010; Browne et al., 2011; Samways et al., 2011), site-directed mutagenesis experiments have shown that substituting side chains in the permeation pathway and intracellular domains can alter the ability of the P2XR to transition between the $\mathrm{I}_{1}$ and $\mathrm{I}_{2}$ permeability states (Khakh et al., 1999a; Khakh and Lester, 1999; Virginio et al., 1999a; Khakh and Egan, 2005; Yan et al., 2008). For P2X7R, substitutions introduced in the N-terminal domain can lock the receptor in an immediately $\mathrm{NMDG}^{+}$permeable $\mathrm{I}_{2}$ state (Yan et al., 2008), supporting the idea that the accommodation of larger polyatomic cations is within the size limits of the intrinsic pore of these ion channels. This argument is further supported by the observation that YO-PRO1 exhibits the characteristics of a permeant blocker of $\mathrm{Na}^{+}$currents when applied to the ATPgated P2X7R (Browne et al., 2013), a result similar to one for the putatively pore dilating TRPV1R (Li et al., 2011).

Accepting that P2XRs have the capability of accommodating larger ionic species of up to $12 \AA$ in diameter (Browne et al., 2013), an important question is whether the transition from $I_{1}$ to $\mathrm{I}_{2}$ during sustained activation is automatic and readily occurs in the absence of large ionic species, or whether the presence of these large species is required to induce $I_{2}$ formation, perhaps via a "foot-in-the-door" mechanism. Two studies have published data relevant to this question, but with conflicting results. With $\mathrm{NMDG}^{+}$as the chief extracellular charge carrier, Jiang et al. (2005) observed that complete pore dilation of P2X7R expressed in HEK293 cells usually occurred within $30 \mathrm{~s}$ of sustained ATP exposure, consistent with previous studies (Khakh et al., 1999a; Virginio et al., 1999a). However, when they exposed the cells to $30 \mathrm{~s}$ of ATP in the presence of normal extracellular saline, and then switched the extracellular $\mathrm{Na}^{+}$for $\mathrm{NMDG}^{+}$in the continued presence of ATP, they observed that the channel's permeability state started in $I_{1}$ and then slowly shifted to $I_{2}$. One interpretation is that $\mathrm{NMDG}^{+}$needs to be present to induce the transition from $I_{1}$ to $I_{2}$. However, a very similar experiment was conducted in GT-1 cells expressing recombinant P2X7Rs, but in this case the substitution of $\mathrm{NMDG}^{+}$for $\mathrm{Na}^{+}$after $60 \mathrm{~s}$ of ATP exposure showed the channel to already be in $\mathrm{I}_{2}$ (Yan et al., 2008), suggesting that the pore widened in the absence of large cations. Establishing the mechanism by which P2XRs transition from the $I_{1}$ to the large cation permeable $I_{2}$ state is a worthy objective for future investigation, particularly in light of the apparent potential for using LGICs with wide pores as conduits for selective delivery of therapeutic drugs into cells (Binshtok et al., 2007; Li et al., 2011).

The hope for the future is that, in addition to the currently available closed and open state models for the P2XRs, a new model showing the putative pore dilated state will be resolved. As it is, there is already compelling evidence from crystallographic data for a similar trimeric family of ion channels, the ASIC receptors, giving credence to the idea that ion channels can occupy multiple conductance states of different diameter (Lingueglia et al., 1997; Baconguis and Gouaux, 2012). In addition, structural data suggests that the diameter of the open channel pore of the bacterial mechanosensitive channel, MscL, can change between 2 and $30 \AA$ depending on the degree to which the pore-forming transmembrane domains tilt relative to one another in the lipid bilayer (Doyle, 2004).

\section{Separate downstream permeation pathways may contribute to some of the observed permeability changes}

Although there is sound evidence supporting the ability for large ionic species to enter and permeate the channel of some P2XRs, this does not necessarily exclude the possibility that separate downstream permeation pathways also contribute to large ion transport. An initial piece of evidence favoring the view that the presence of other proteins, whether channel forming or not, might be necessary for the observed time-dependent changes in membrane permeability witnessed during prolonged ATP exposure was that the appearance of the phenomenon is far from consistent. Even in overexpression systems, the progressive increase in membrane permeability to large cations during prolonged ATP exposure often only occurs in a subset of the cells studied (Virginio et al., 1999a), and in other cases studies have failed to reproduce the phenomenon at all (Petrou et al., 1997; Klapperstuck et al., 2000; Pannicke et al., 2000). This may be due to the $I_{1}$ to $I_{2}$ transition being dependent on modification 
of the P2XR channel by kinases or phosphatases, but may also be due to the need for some separate pore forming protein to be co-expressed in the same cells as the activated P2XRs. In some cases, a mismatch between the observed increase in large cation permeability of P2X7R mediated currents using electrophysiology, and observed uptake of cationic dyes in intact cell imaging experiments, suggests that at least some dye uptake might occur through a non-P2X7R-mediated pathway (Virginio et al., 1997; Jiang et al., 2005). Additionally, single channel studies in macrophages revealed that prolonged ATP exposure was associated with the openings of a large conductance $(\sim 400 \mathrm{pS})$ pore permeable to large anions and cations (Faria et al., 2005), but these high conductance openings have not been observed in single channel studies of the recombinant P2X7R (Riedel et al., 2007). Furthermore, the increased permeability of macrophages to large ionic species during sustained ATP-exposure was found to be dependent on Phospholipase C-mediated elevations in $\left[\mathrm{Ca}^{2+}\right]_{i}$ and MAP kinase, despite the fact that inhibition of neither of these pathways had any effect on P2X7R-mediated currents (DonnellyRoberts et al., 2004; Faria et al., 2009).

A possible candidate for a putative secondary ion transport pathway was the gap junction-forming protein, Pannexin-1. A growing body of evidence suggests that there is a functionally significant interaction between P2X7R and Pannexin-1 (Pelegrin and Surprenant, 2006; Locovei et al., 2007; Gulbransen et al., 2012; Poornima et al., 2012; Xu et al., 2012), raising the compelling possibility that the latter is responsible for some of the observed ATP-dependent increase in membrane permeability to larger ionic species. Regardless, successive studies have shown that neither pharmacological blockade of Pannexin-1 nor inhibiting its expression affects the observed time-dependent change in permeability observed for P2X2R (Chaumont et al., 2008) P2X4R (Bernier et al., 2012), or P2X7R (Yan et al., 2008; Alberto et al., 2013). In addition, it appears that Pannexin-1 is directly inhibited by ATP within the relatively high concentration range required to activate native $\mathrm{P} 2 \mathrm{X} 7 \mathrm{R}$ receptors (Qiu and Dahl, 2009).

In cases in which prolonged ATP exposure correlates with an increase in membrane permeability to anionic species, the argument for a secondary permeation pathway independent of the P2XR pore itself is more compelling. Cankurtaran-Sayar et al. (2009) observed an ATP-mediated increase in permeability to large anions in HEK293 cells transfected with P2X7R, but found that this was due to a $\mathrm{Ca}^{2+}$-dependent mechanism separate from that mediating permeability to large cations. Results from a study by Schachter et al. (2008) go as far as to suggests that, in some cases, the ATP-dependent increase in permeability to anions might occur irrespective of whether there are functional P2XRs present; a result that urges caution in studying P2XR pore dilation in cell models that likely contain other purinergic receptors coupled to second messenger cascades, which might be linked to these other permeabilizing pathways. Given that Pannexin-1 channels have been shown to be permeable to large anions (Ma et al., 2012; Poornima et al., 2012), it may yet transpire that these proteins have a role to play in ATP-mediated increases in membrane permeability to large ionic species in some settings.

\section{CONCLUSION}

The current understanding of ion permeation through the members of the P2X receptor family of cation permeable ion channels can be summarized as follows. Regardless of whether the P2X receptor is in the closed or open conformation, extracellular ions likely diffuse freely between the bulk solution and the extracellular vestibule of the channel by way of the three large intersubunit lateral portals. Upon ATP binding, signal transduction and channel gating, the TM domains withdraw from the central axis of the pore, iris-like, thus relieving the constriction formed by the TM2 domains in the closed channel state (Figure 6). Extracellular ions can then enter and conduct through the revealed transmembrane permeation pathway into the cell. Rather than a specific structural locus existing for ion selectivity, the data suggest that a number of sites within the open channel permeation pathway, some within the lateral portals and some deep within the narrow transmembrane pore, contribute to this essential ion channel property. Indeed, ion selection and conductance appear to be dynamic properties of P2XRs, with the ion permeable pore potentially inhabiting multiple open states with distinct permeation properties (Khakh and Lester, 1999; Virginio et al., 1999a; Samways et al., 2012).

Several questions remain, but one that is arguably of a particular pressing nature is precisely how these channels exhibit a preference for cations over anions. And extension of this question would include how some P2X receptors can become increasingly permeable to very large polyatomic cation species without apparently attenuating their ability to discriminate between small monovalent cations and anions. Another question is what role the intracellular domains play in ion permeation, whether direct by virtue of interacting with entering and exiting ions on the intracellular side of the membrane, or indirectly via effects on the arrangements of the TM domains in the open channel state.

\section{ACKNOWLEDGEMENTS}

We wish to thank Dr. Liam Browne (Children's Hospital Boston, $\mathrm{MA}$ ) for providing us with the open and closed homology structures for P2X2R. All figure images were produced using PyMOL Molecular Graphics System, Version 1.5.0.4 Schrödinger, LLC.

\section{REFERENCES}

Adinolfi, E., Pizzirani, C., Idzko, M., Panther, E., Norgauer, J., Di Virgilio, F., et al. (2005). P2X(7)Receptor: death or life? Purinergic Signal. 1, 219-227. doi: 10.1007/s11302-005-6322-X

Alberto, A. V., Faria, R. X., Couto, C. G., Ferreira, L. G., Souza, C. A., Teixeira, P. C., et al. (2013). Is pannexin the pore associated with the P2X7 receptor? Naunyn Schmiedebergs Arch. Pharmacol. 386, 775-787. doi: 10.1007/s00210-013-0868-x

Albuquerque, E. X., Pereira, E. F., Alkondon, M., and Rogers, S. W. (2009). Mammalian nicotinic acetylcholine receptors: from structure to function. Physiol. Rev. 89, 73-120. doi: 10.1152/physrev.00015.2008

Allsopp, R. C., El Ajouz, S., Schmid, R., and Evans, R. J. (2011). Cysteine scanning mutagenesis (residues Glu52-Gly96) of the human P2X1 receptor for ATP: mapping agonist binding and channel gating. J. Biol. Chem. 286, 29207-29217. doi: 10.1074/jbc.M111.260364

Aschrafi, A., Sadtler, S., Niculescu, C., Rettinger, J., and Schmalzing, G. (2004). Trimeric architecture of homomeric $\mathrm{P} 2 \mathrm{X} 2$ and heteromeric $\mathrm{P} 2 \mathrm{X} 1+2$ receptor subtypes. J. Mol. Biol. 342, 333-343. doi: 10.1016/j.jmb.2004.06.092

Baconguis, I., and Gouaux, E. (2012). Structural plasticity and dynamic selectivity of acid-sensing ion channel-spider toxin complexes. Nature 489, 400-405. doi: 10.1038 /nature 11375 
Banke, T. G., Chaplan, S. R., and Wickenden, A. D. (2010). Dynamic changes in the TRPAl selectivity filter lead to progressive but reversible pore dilation. Am. J. Physiol. Cell Physiol. 298, C1457-C1468. doi: 10.1152/ajpcell.00489.2009

Barrera, N. P., Ormond, S. J., Henderson, R. M., Murrell-Lagnado, R. D., and Edwardson, J. M. (2005). AFM imaging demonstrates that P2X2 receptors are trimers, but that P2X6 receptor subunits do not oligomerize. J. Biol. Chem. 280, 10759-10765. doi: 10.1074/jbc.M412265200

Benham, C. D., Bouvier, M. M., and Evans, M. L. (1991). Changes in cytoplasmic calcium induced by purinergic $\mathrm{P} 2 \mathrm{x}$ receptor activation in vascular smooth muscle cells and sensory neurons. Adv. Exp. Med. Biol. 304, 229-239. doi: 10.1007/978-1-4684-6003-2_19

Bernier, L. P., Ase, A. R., Boue-Grabot, E., and Seguela, P. (2012). P2X4 receptor channels form large noncytolytic pores in resting and activated microglia. Glia 60, 728-737. doi: 10.1002/glia.22301

Binshtok, A. M., Bean, B. P., and Woolf, C. J. (2007). Inhibition of nociceptors by TRPV1-mediated entry of impermeant sodium channel blockers. Nature 449, 607-610. doi: 10.1038/nature06191

Bo, X., Jiang, L. H., Wilson, H. L., Kim, M., Burnstock, G., Surprenant, A., et al. (2003). Pharmacological and biophysical properties of the human P2X5 receptor. Mol. Pharmacol. 63, 1407-1416. doi: 10.1124/mol.63.6.1407

Boehm, S. (1999). ATP stimulates sympathetic transmitter release via presynaptic P2X purinoceptors. J. Neurosci. 19, 737-746.

Boue-Grabot, E., Archambault, V., and Seguela, P. (2000). A protein kinase C site highly conserved in P2X subunits controls the desensitization kinetics of P2X(2) ATP-gated channels. J. Biol. Chem. 275, 10190-10195. doi: 10.1074/jbc.275.14.10190

Brain, K. L., Cuprian, A. M., Williams, D. J., and Cunnane, T. C. (2003). The sources and sequestration of $\mathrm{Ca}(2+)$ contributing to neuroeffector $\mathrm{Ca}(2+)$ transients in the mouse vas deferens. J. Physiol. 553, 627-635. doi: 10.1113/jphysiol.2003.049734

Brake, A. J., Wagenbach, M. J., and Julius, D. (1994). New structural motif for ligand-gated ion channels defined by an ionotropic ATP receptor. Nature 371, 519-523. doi: 10.1038/371519a0

Bretschneider, F., Klapperstuck, M., Lohn, M., and Markwardt, F. (1995) Nonselective cationic currents elicited by extracellular ATP in human Blymphocytes. Pflugers Arch. 429, 691-698. doi: 10.1007/BF00373990

Browne, L. E., Cao, L., Broomhead, H. E., Bragg, L., Wilkinson, W. J., and North, R. A. (2011). P2X receptor channels show threefold symmetry in ionic charge selectivity and unitary conductance. Nat. Neurosci. 14, 17-18. doi: $10.1038 / \mathrm{nn} .2705$

Browne, L. E., Compan, V., Bragg, L., and North, R. A. (2013). P2X7 receptor channels allow direct permeation of nanometer-sized dyes. J. Neurosci. 33 3557-3566. doi: 10.1523/JNEUROSCI.2235-12.2013

Burnashev, N. (1998). Calcium permeability of ligand-gated channels. Cell Calcium 24, 325-332. doi: 10.1016/S0143-4160(98)90056-2

Burnstock, G., and Kennedy, C. (2011). P2X receptors in health and disease. Adv. Pharmacol. 61, 333-372. doi: 10.1016/B978-0-12-385526-8.00011-4

Cankurtaran-Sayar, S., Sayar, K., and Ugur, M. (2009). P2X7 receptor activates multiple selective dye-permeation pathways in RAW 264.7 and human embryonic kidney 293 cells. Mol. Pharmacol. 76, 1323-1332. doi: 10.1124/mol.109.059923

Carattino, M. D., and Della Vecchia, M. C. (2012). Contribution of residues in second transmembrane domain of ASIC1a protein to ion selectivity. J. Biol. Chem. 287, 12927-12934. doi: 10.1074/jbc.M111.329284

Catterall, W. A. (2012). Voltage-gated sodium channels at 60: structure, function and pathophysiology. J. Physiol. 590, 2577-2589. doi: 10.1113/jphysiol.2011.224204

Catterall, W. A., Raman, I. M., Robinson, H. P., Sejnowski, T. J., and Paulsen, O. (2012). The Hodgkin-Huxley heritage: from channels to circuits. J. Neurosci. 32, 14064-14073. doi: 10.1523/JNEUROSCI.3403-12.2012

Chaumont, S., Compan, V., Toulme, E., Richler, E., Housley, G. D., Rassendren, F., et al. (2008) Regulation of P2X2 receptors by the neuronal calcium sensor VILIP1. Sci. Signal. 1, ra8. doi: 10.1126/scisignal.1162329

Chung, M. K., Guler, A. D., and Caterina, M. J. (2008). TRPV1 shows dynamic ionic selectivity during agonist stimulation. Nat. Neurosci. 11, 555-564. doi: 10.1038/nn.2102

Coddou, C., Yan, Z., Obsil, T., Huidobro-Toro, J. P., and Stojilkovic, S. S. (2011). Activation and regulation of purinergic P2X receptor channels. Pharmacol. Rev. 63, 641-683. doi: 10.1124/pr.110.003129
Compan, V., Ulmann, L., Stelmashenko, O., Chemin, J., Chaumont, S., and Rassendren, F. (2012). P2X2 and P2X5 subunits define a new heteromeric receptor with P2X7-like properties J. Neurosci. 32, 4284-4296. doi: 10.1523/JNEUROSCI.6332-11.2012

Cook, S. P., Vulchanova, L., Hargreaves, K. M., Elde, R., and McCleskey, E. W. (1997). Distinct ATP receptors on pain-sensing and stretch-sensing neurons. Nature 387, 505-508. doi: 10.1038/387505a0

Costa-Junior, H. M., Sarmento Vieira, F., and Coutinho-Silva, R. (2011). Terminus of the P2X7 receptor: treasure hunting. Purinergic Signal. 7, 7-19. doi: 10.1007/s11302-011-9215-1

Ding, S., and Sachs, F. (1999a). Ion permeation and block of P2X(2) purinoceptors: single channel recordings. J. Membr. Biol. 172, 215-223. doi: $10.1007 / \mathrm{s} 002329900598$

Ding, S., and Sachs, F. (1999b). Single channel properties of P2X2 purinoceptors. J. Gen. Physiol. 113, 695-720. doi: 10.1085/jgp.113.5.695

Di Virgilio, F. (2012). Purines, purinergic receptors, and cance. Cancer Res. 72, 5441-5447. doi: 10.1158/0008-5472.CAN-12-1600

Dokmanic, I., Sikic, M., and Tomic, S. (2008). Metals in proteins: correlation between the metal-ion type, coordination number and the amino-acid residues involved in the coordination. Acta Crystallogr. D Biol. Crystallogr. 64, 257-263. doi: 10.1107/S090744490706595X

Donnelly-Roberts, D. L., Namovic, M. T., Faltynek, C. R., and Jarvis, M. F. (2004). Mitogen-activated protein kinase and caspase signaling pathways are required for $\mathrm{P} 2 \mathrm{X} 7$ receptor $(\mathrm{P} 2 \mathrm{X} 7 \mathrm{R})$-induced pore formation in human THP-1 cells. J. Pharmacol. Exp. Ther. 308, 1053-1061. doi: 10.1124/jpet.103. 059600

Dowd, E., McQueen, D. S., Chessell, I. P., and Humphrey, P. P. (1998). P2X receptormediated excitation of nociceptive afferents in the normal and arthritic rat knee joint. Br. J. Pharmacol. 125, 341-346. doi: 10.1038/sj.bjp.0702080

Doyle, D. A. (2004). Structural changes during ion channel gating. Trends Neurosci. 27, 298-302. doi: 10.1016/j.tins.2004.04.004

Egan, T. M., Haines, W. R., and Voigt, M. M. (1998). A domain contributing to the ion channel of ATP-gated $\mathrm{P} 2 \mathrm{X} 2$ receptors identified by the substituted cysteine accessibility method. J. Neurosci. 18, 2350-2359.

Egan, T. M., and Khakh, B. S. (2004). Contribution of calcium ions to P2X channel responses. J. Neurosci. 24, 3413-3420. doi: 10.1523/JNEUROSCI.5429-03.2004

Egan, T. M., Samways, D. S., and Li, Z. (2006). Biophysics of P2X receptors. Pflugers Arch. 452, 501-512. doi: 10.1007/s00424-006-0078-1

Eisenman, G., and Dani, J. A. (1987). An introduction to molecular architecture and permeability of ion channels. Annu. Rev. Biophys. Biophys. Chem. 16, 205-226. doi: 10.1146/annurev.bb.16.060187.001225

Eisenman, G., and Horn, R. (1983). Ionic selectivity revisited: the role of kinetic and equilibrium processes in ion permeation through channels. J. Membr. Biol. 76, 197-225. doi: 10.1007/BF01870364

Ennion, S. J., and Evans, R. J. (2002). P2X(1) Receptor subunit contribution to gating revealed by a dominant negative PKC mutant. Biochem. Biophys. Res. Commun. 291, 611-616. doi: 10.1006/bbrc.2002.6488

Evans, R. J. (1996). Single channel properties of ATP-gated cation channels (P2X receptors) heterologously expressed in Chinese hamster ovary cells. Neurosci. Lett. 212, 212-214. doi: 10.1016/0304-3940(96)12804-4

Evans, R. J., Lewis, C., Virginio, C., Lundstrom, K., Buell, G., Surprenant, A., et al. (1996). Ionic permeability of, and divalent cation effects on, two ATPgated cation channels (P2X receptors) expressed in mammalian cells. J. Physiol. 497(Pt 2), 413-422.

Faria, R. X., Defarias, F. P., and Alves, L. A. (2005). Are second messengers crucial for opening the pore associated with P2X7 receptor? Am. J. Physiol. Cell Physiol. 288, C260-C271. doi: 10.1152/ajpcell.00215.2004

Faria, R. X., Reis, R. A., Casabulho, C. M., Alberto, A. V., de Farias, F. P., Henriques-Pons, A., et al. (2009). Pharmacological properties of a pore induced by raising intracellular Ca2+. Am. J. Physiol. Cell Physiol. 297, C28-C42. doi: 10.1152/ajpcell.00476.2008

Fountain, S. J., Cao, L., Young, M. T., and North, R. A. (2008). Permeation properties of a P2X receptor in the green algae Ostreococcus tauri. J. Biol. Chem. 283 15122-15126. doi: 10.1074/jbc.M801512200

Fucile, S. (2004). Ca2+ permeability of nicotinic acetylcholine receptors. Cell Calcium 35, 1-8. doi: 10.1016/j.ceca.2003.08.006

Garcia-Guzman, M., Soto, F., Gomez-Hernandez, J. M., Lund, P. E., and Stuhmer, W. (1997). Characterization of recombinant human P2X4 receptor reveals 
pharmacological differences to the rat homologue. Mol. Pharmacol. 51, $109-118$.

Gulbransen, B. D., Bashashati, M., Hirota, S. A., Gui, X., Roberts, J. A., MacDonald, J. A., et al. (2012). Activation of neuronal P2X7 receptor-pannexin-1 mediates death of enteric neurons during colitis. Nat. Med. 18, 600-604. doi: 10.1038/nm.2679

Haines, W. R., Migita, K., Cox, J. A., Egan, T. M., and Voigt, M. M. (2001). The first transmembrane domain of the $\mathrm{P} 2 \mathrm{X}$ receptor subunit participates in the agonist-induced gating of the channel. J. Biol. Chem. 276, 32793-32798. doi: 10.1074/jbc.M104216200

Hattori, M., and Gouaux, E. (2012). Molecular mechanism of ATP binding and ion channel activation in P2X receptors. Nature 485, 207-212. doi: 10.1038 /nature1 1010

Heymann, G., Dai, J., Li, M., Silberberg, S. D., Zhou, H. X., and Swartz, K. J. (2013). Inter- and intrasubunit interactions between transmembrane helices in the open state of P2X receptor channels. Proc. Natl. Acad. Sci. U.S.A. 110, E4045-E4054. doi: 10.1073/pnas.1311071110

Hille, B. (2001). Ion Channels of Excitable Membranes, 3nd Edn. Sunderland, MA: Sinauer Associates, 441-574.

Holmgren, M., Shin, K. S., and Yellen, G. (1998). The activation gate of a voltagegated $\mathrm{K}+$ channel can be trapped in the open state by an intersubunit metal bridge. Neuron 21, 617-621. doi: 10.1016/S0896-6273(00)80571-1

Jatzke, C., Watanabe, J., and Wollmuth, L. P. (2002). Voltage and concentration dependence of $\mathrm{Ca}(2+)$ permeability in recombinant glutamate receptor subtypes. J. Physiol. 538, 25-39. doi: 10.1113/jphysiol.2001.012897

Jiang, L. H., Kim, M., Spelta, V., Bo, X., Surprenant, A., and North, R. A. (2003). Subunit arrangement in P2X receptors. J. Neurosci. 23, 8903-8910.

Jiang, L. H., Rassendren, F., Mackenzie, A., Zhang, Y. H., Surprenant, A., and North, R. A. (2005). N-methyl-D-glucamine and propidium dyes utilize different permeation pathways at rat $\mathrm{P} 2 \mathrm{X}(7)$ receptors. Am. J. Physiol. Cell Physiol. 289, C1295-C1302. doi: 10.1152/ajpcell.00253.2005

Jiang, L. H., Rassendren, F., Spelta, V., Surprenant, A., and North, R. A. (2001). Amino acid residues involved in gating identified in the first membranespanning domain of the rat P2X(2) receptor. J. Biol. Chem. 276, 14902-14908. doi: 10.1074/jbc.M011327200

Jiang, R., Martz, A., Gonin, S., Taly, A., de Carvalho, L. P., and Grutter, T. (2010). A putative extracellular salt bridge at the subunit interface contributes to the ion channel function of the ATP-gated P2X2 receptor. J. Biol. Chem. 285, 15805-15815. doi: 10.1074/jbc.M110.101980

Kaczmarek-Hajek, K., Lorinczi, E., Hausmann, R., and Nicke, A. (2012). Molecular and functional properties of P2X receptors-recent progress and persisting challenges. Purinergic Signal. 8, 375-417. doi: 10.1007/s11302-0129314-7

Kawate, T., Michel, J. C., Birdsong, W. T., and Gouaux, E. (2009). Crystal structure of the ATP-gated P2X(4) ion channel in the closed state. Nature 460, 592-598. doi: $10.1038 /$ nature 08198

Kawate, T., Robertson, J. L., Li, M., Silberberg, S. D., and Swartz, K. J. (2011). Ion access pathway to the transmembrane pore in P2X receptor channels. J. Gen. Physiol. 137, 579-590. doi: 10.1085/jgp.201010593

Keramidas, A., Moorhouse, A. J., Schofield, P. R., and Barry, P. H. (2004). Ligandgated ion channels: mechanisms underlying ion selectivity. Prog. Biophys. Mol. Biol. 86, 161-204. doi: 10.1016/j.pbiomolbio.2003.09.002

Khakh, B. S., Bao, X. R., Labarca, C., and Lester, H. A. (1999a). Neuronal P2X transmitter-gated cation channels change their ion selectivity in seconds. Nat. Neurosci. 2, 322-330. doi: 10.1038/7233

Khakh, B. S., Proctor, W. R., Dunwiddie, T. V., Labarca, C., and Lester, H. A. (1999b). Allosteric control of gating and kinetics at P2X(4) receptor channels. J. Neurosci. 19, 7289-7299.

Khakh, B. S., and Egan, T. M. (2005). Contribution of transmembrane regions to ATP-gated P2X2 channel permeability dynamics. J. Biol. Chem. 280, 6118-6129. doi: 10.1074/jbc.M411324200

Khakh, B. S., and Henderson, G. (1998). ATP receptor-mediated enhancement of fast excitatory neurotransmitter release in the brain. Mol. Pharmacol. 54, 372-378.

Khakh, B. S., and Henderson, G. (2000). Modulation of fast synaptic transmission by presynaptic ligand-gated cation channels. J. Auton. Nerv. Syst. 81, 110-121. doi: 10.1016/S0165-1838(00)00111-9

Khakh, B. S., and Lester, H. A. (1999). Dynamic selectivity filters in ion channels. Neuron 23, 653-658. doi: 10.1016/S0896-6273(01)80025-8
Khakh, B. S., and North, R. A. (2006). P2X receptors as cell-surface ATP sensors in health and disease. Nature 442, 527-532. doi: 10.1038/nature04886

King, B. F., Townsend-Nicholson, A., Wildman, S. S., Thomas, T., Spyer, K. M., and Burnstock, G. (2000). Coexpression of rat P2X2 and P2X6 subunits in Xenopus oocytes. J. Neurosci. 20, 4871-4877.

Kirkup, A. J., Booth, C. E., Chessell, I. P., Humphrey, P. P., and Grundy, D. (1999). Excitatory effect of $\mathrm{P} 2 \mathrm{X}$ receptor activation on mesenteric afferent nerves in the anaesthetised rat. J. Physiol. 520(Pt 2), 551-563. doi: 10.1111/j.14697793.1999.00551.x

Klapperstuck, M., Buttner, C., Bohm, T., Schmalzing, G., and Markwardt, F. (2000). Characteristics of P2X7 receptors from human B lymphocytes expressed in Xenopus oocytes. Biochim. Biophys. Acta. 1467, 444-456. doi: 10.1016/S00052736(00)00245-5

Kracun, S., Chaptal, V., Abramson, J., and Khakh, B. S. (2010). Gated access to the pore of a P2X receptor: structural implications for closed-open transitions. J. Biol. Chem. 285, 10110-10121. doi: 10.1074/jbc.M109.089185

Krovetz, H. S., VanDongen, H. M., and VanDongen, A. M. (1997). Atomic distance estimates from disulfides and high-affinity metal-binding sites in a $\mathrm{K}+$ channel pore. Biophys. J. 72, 117-126. doi: 10.1016/S0006-3495(97)78651-X

Kurz, L. L., Zuhlke, R. D., Zhang, H. J., and Joho, R. H. (1995). Side-chain accessibilities in the pore of a $\mathrm{K}+$ channel probed by sulfhydryl-specific reagents after cysteine-scanning mutagenesis. Biophys. J. 68, 900-905. doi: 10.1016/S00063495(95)80266-3

Kwan, D. C., Prole, D. L., and Yellen, G. (2012). Structural changes during HCN channel gating defined by high affinity metal bridges. J. Gen. Physiol. 140, 279-291. doi: 10.1085/jgp.201210838

Lamont, C., and Wier, W. G. (2002). Evoked and spontaneous purinergic junctional Ca2+ transients (jCaTs) in rat small arteries. Circ. Res. 91, 454-456. doi: 10.1161/01.RES.0000035060.98415.4B

Le, K. T., Villeneuve, P., Ramjaun, A. R., McPherson, P. S., Beaudet, A., and Seguela, P. (1998). Sensory presynaptic and widespread somatodendritic immunolocalization of central ionotropic P2X ATP receptors Neuroscience 83, 177-190. doi: 10.1016/S0306-4522(97)00365-5

Lewis, C., Neidhart, S., Holy, C., North, R. A., Buell, G., and Surprenant, A. (1995). Coexpression of P2X2 and P2X3 receptor subunits can account for ATP-gated currents in sensory neurons Nature 377, 432-435. doi: 10.1038/37 $7432 \mathrm{a} 0$

Li, H., Wang, S., Chuang, A. Y., Cohen, B. E., and Chuang, H. H. (2011). Activitydependent targeting of TRPV1 with a pore-permeating capsaicin analog. Proc. Natl. Acad. Sci. U.S.A. 108, 8497-8502. doi: 10.1073/pnas.1018550108

Li, M., Chang, T. H., Silberberg, S. D., and Swartz, K. J. (2008). Gating the pore of P2X receptor channels. Nat. Neurosci. 11, 883-887. doi: 10.1038/ nn. 2151

Li, M., Kawate, T., Silberberg, S. D., and Swartz, K. J. (2010). Pore-opening mechanism in trimeric $\mathrm{P} 2 \mathrm{X}$ receptor channels. Nat. Commun. 1, 44. doi: 10.1038/ncomms 1048

Lingueglia, E., de Weille, J. R., Bassilana, F., Heurteaux, C., Sakai, H., Waldmann, R., et al. (1997). A modulatory subunit of acid sensing ion channels in brain and dorsal root ganglion cells. J. Biol. Chem. 272, 29778-29783. doi: 10.1074/jbc.272.47.29778

Liu, Y., Holmgren, M., Jurman, M. E., and Yellen, G. (1997). Gated access to the pore of a voltage-dependent K+ channel. Neuron 19, 175-184. doi: 10.1016/S0896-6273(00)80357-8

Locovei, S., Scemes, E., Qiu, F., Spray, D. C., and Dahl, G. (2007). Pannexinl is part of the pore forming unit of the $\mathrm{P} 2 \mathrm{X}(7)$ receptor death complex. FEBS Lett. 581, 483-488. doi: 10.1016/j.febslet.2006.12.056

Lu, Q., and Miller, C. (1995). Silver as a probe of pore-forming residues in a potassium channel. Science 268, 304-307. doi: 10.1126/science.7716526

Ma, W., Compan, V., Zheng, W., Martin, E., North, R. A., Verkhratsky, A., et al. (2012). Pannexin 1 forms an anion-selective channel. Pflugers Arch. 463, 585-592. doi: 10.1007/s00424-012-1077-z

MacKinnon, R. (2003). Potassium channels. FEBS Lett. 555, 62-65. doi: 10.1016/S0014-5793(03)01104-9

Mathie, A., Cull-Candy, S. G., and Colquhoun, D. (1991). Conductance and kinetic properties of single nicotinic acetylcholine receptor channels in rat sympathetic neurones. J. Physiol. 439, 717-750.

Migita, K., Haines, W. R., Voigt, M. M., and Egan, T. M. (2001). Polar residues of the second transmembrane domain influence cation permeability of the ATP-gated P2X(2) receptor. J. Biol. Chem. 276, 30934-30941. doi: 10.1074/jbc.M103366200 
Neher, E. (1995). The use of fura-2 for estimating Ca buffers and Ca fluxes. Neuropharmacology 34, 1423-1442. doi: 10.1016/0028-3908(95)00144-U

Newbolt, A., Stoop, R., Virginio, C., Surprenant, A., North, R. A., Buell, G., et al. (1998). Membrane topology of an ATP-gated ion channel (P2X receptor). J. Biol. Chem. 273, 15177-15182. doi: 10.1074/jbc.273.24.15177

Nicke, A., Baumert, H. G., Rettinger, J., Eichele, A., Lambrecht, G., Mutschler, E., et al. (1998). P2X1 and P2X3 receptors form stable trimers: a novel structural motif of ligand-gated ion channels. Embo J. 17, 3016-3028. doi: $10.1093 / \mathrm{emboj} / 17.11 .3016$

Nicke, A., Kuan, Y. H., Masin, M., Rettinger, J., Marquez-Klaka, B., Bender, O., et al. (2009). A functional P2X7 splice variant with an alternative transmembrane domain 1 escapes gene inactivation in P2X7 knock-out mice. J. Biol. Chem. 284, 25813-25822. doi: 10.1074/jbc.M109.033134

Norenberg, W., Gobel, I., Meyer, A., Cox, S. L., Starke, K., and Trendelenburg, A. U. (2001). Stimulation of mouse cultured sympathetic neurons by uracil but not adenine nucleotides 103, 227-236. doi: 10.1016/S0306-4522(00)00547-9

North, R. A. (2002) Molecular physiology of P2X receptors. Physiol. Rev. 82, 1013-1067. doi: 10.1152/physrev.00015.2002

North, R. A., and Jarvis, M. F. (2013). P2X receptors as drug targets. Mol. Pharmacol. 83, 759-769. doi: 10.1124/mol.112.083758

Nuttle, L. C., and Dubyak, G. R. (1994). Differential activation of cation channels and non-selective pores by macrophage $\mathrm{P} 2 \mathrm{z}$ purinergic receptors expressed in xenopus oocytes. J. Biol. Chem. 269, 13988-13996.

Pannicke, T., Fischer, W., Biedermann, B., Schadlich, H., Grosche, J., Faude, F., et al. (2000). P2X7 receptors in Muller glial cells from the human retina. J. Neurosci. 20, 5965-5972.

Pelegrin, P. (2011). Many ways to dilate the P2X7 receptor pore. Br. J. Pharmacol. 163, 908-911. doi: 10.1111/j.1476-5381.2011.01325.x

Pelegrin, P., and Surprenant, A. (2006). Pannexin-1 mediates large pore formation and interleukin-1beta release by the ATP-gated P2X7 receptor. EMBO J. 25, 5071-5082. doi: 10.1038/sj.emboj.7601378

Petrou, S., Ugur, M., Drummond, R. M., Singer, J. J., and Walsh, J. V. Jr. (1997). P2X7 purinoceptor expression in Xenopus oocytes is not sufficient to produce a pore-forming P2Z-like phenotype. FEBS Lett. 411, 339-345. doi: 10.1016/S0014-5793(97)00700-X

Poornima, V., Madhupriya, M., Kootar, S., Sujatha, G., Kumar, A., and Bera, A. K. (2012). P2X7 receptor-pannexin 1 hemichannel association: effect of extracellular calcium on membrane permeabilization. J. Mol. Neurosci. 46, 585-594. doi: 10.1007/s12031-011-9646-8

Premkumar, L. S., Agarwal, S., and Steffen, D. (2002). Single-channel properties of native and cloned rat vanilloid receptors. J. Physiol. 545, 107-117. doi: 10.1113/jphysiol.2002.016352

Priel, A., and Silberberg, S. D. (2004). Silberberg, Mechanism of ivermectin facilitation of human P2X4 receptor channels. J. Gen. Physiol. 123, 281-293. doi: 10.1085/jgp.200308986

Qiu, F., and Dahl, G. (2009). A permeant regulating its permeation pore: inhibition of pannexin 1 channels by ATP. Am. J. Physiol. Cell Physiol. 296, C250-C255. doi: 10.1152/ajpcell.00433.2008

Rassendren, F., Buell, G., Newbolt, A., North, R. A., and Surprenant, A. (1997). Identification of amino acid residues contributing to the pore of a $\mathrm{P} 2 \mathrm{X}$ receptor. Embo. J. 16, 3446-3454. doi: 10.1093/emboj/16.12.3446

Riedel, T., Lozinsky, I., Schmalzing, G., and Markwardt, F. (2007). Kinetics of P2X7 receptor-operated single channels currents. Biophys. J. 92, 2377-2391. doi: 10.1529/biophysj.106.091413

Roberts, J. A., Allsopp, R. C., El Ajouz, S., Vial, C., Schmid, R., Young, M. T., et al. (2012a). Agonist binding evokes extensive conformational changes in the extracellular domain of the ATP-gated human P2X1 receptor ion channel. Proc. Natl. Acad. Sci. U.S.A. 109, 4663-4667. doi: 10.1073/pnas.1201872109

Roberts, J. A., Bottrill, A. R., Mistry, S., and Evans, R. J. (2012b). Mass spectrometry analysis of human P2X1 receptors; insight into phosphorylation, modelling and conformational changes. J. Neurochem. 123, 725-735. doi: 10.1111/ jnc. 12012

Roberts, J. A., and Evans, R. J. (2007). Cysteine substitution mutants give structural insight and identify ATP binding and activation sites at P2X receptors. J. Neurosci. 27, 4072-4082. doi: 10.1523/JNEUROSCI.2310-06.2007

Roberts, J. A., Vial, C., Digby, H. R., Agboh, K. C., Wen, H., Atterbury-Thomas, A., et al. (2006). Molecular properties of P2X receptors. Pflugers Arch. 452, 486-500. doi: 10.1007/s00424-006-0073-6
Rogers, M., and Dani, J. A. (1995). Comparison of quantitative calcium flux through NMDA, ATP, and ACh receptor channels. Biophys. J. 68, 501-506. doi: 10.1016/S0006-3495(95)80211-0

Rong, W., and Burnstock, G. (2004). Activation of ureter nociceptors by exogenous and endogenous ATP in guinea pig. Neuropharmacology 47, 1093-1101. doi: 10.1016/j.neuropharm.2004.08.003

Roux, B. (2005). Ion conduction and selectivity in $\mathrm{K}(+)$ channels. Annu. Rev. Biophys. Biomol. Struct. 34, 153-171. doi: 10.1146/annurev.biophys.34.040204.144655

Ruppelt, A., Ma, W., Borchardt, K., Silberberg, S. D., and Soto, F. (2001). Genomic structure, developmental distribution and functional properties of the chicken P2X(5) receptor. J. Neurochem. 77, 1256-1265. doi: 10.1046/j.14714159.2001.00348.x

Samways, D. S., and Egan, T. M. (2007). Acidic amino acids impart enhanced Ca2+ permeability and flux in two members of the ATP-gated P2X receptor family. J. Gen. Physiol. 129, 245-256. doi: 10.1085/jgp.200609677

Samways, D. S., and Egan, T. M. (2011). Calcium-dependent decrease in the single-channel conductance of TRPV1. Pflugers Arch. 462, 681-691. doi: 10.1007/s00424-011-1013-7

Samways, D. S., Khakh, B. S., Dutertre, S., and Egan, T. M. (2011). Preferential use of unobstructed lateral portals as the access route to the pore of human ATP-gated ion channels (P2X receptors). Proc. Natl. Acad. Sci. U.S.A. 108, 13800-13805. doi: 10.1073/pnas.1017550108

Samways, D. S., Migita, K., Li, Z., and Egan, T. M. (2008a). On the role of the first transmembrane domain in cation permeability and flux of the ATP-gated P2X2 receptor. J. Biol. Chem. 283, 5110-5117. doi: 10.1074/jbc.M708713200

Samways, D. S., Khakh, B. S., and Egan, T. M. (2008b). Tunable calcium current through TRPV1 receptor channels. J. Biol. Chem. 283, 31274-31278. doi: 10.1074/jbc.C800131200

Samways, D. S., Khakh, B. S., and Egan, T. M. (2012). Allosteric modulation of $\mathrm{Ca} 2+$ flux in a ligand-gated cation channel (P2X4) by actions on lateral portals. J. Biol. Chem. 287, 7594-7602. doi: 10.1074/jbc.M111.322461

Sather, W. A., and McCleskey, E. W. (2003). Permeation and selectivity in calcium channels. Annu. Rev. Physiol. 65, 133-159. doi: 10.1146/annurev.physiol.65.092101.142345

Schachter, J., Motta, A. P., de Souza Zamorano, A., da Silva-Souza, H. A., Guimaraes, M. Z., and Persechini, P. M. (2008). ATP-induced P2X7-associated uptake of large molecules involves distinct mechanisms for cations and anions in macrophages. J. Cell Sci. 121, 3261-3270. doi: 10.1242/jcs.029991

Sine, S. M., Wang, H. L., Hansen, S., and Taylor, P. (2010). On the origin of ion selectivity in the Cys-loop receptor family. J. Mol. Neurosci. 40, 70-76. doi: 10.1007/s12031-009-9260-1

Smith, N. C., and Burnstock, G. (2004). Mechanisms underlying postjunctional synergism between responses of the vas deferens to noradrenaline and ATP. Eur. J. Pharmacol. 498, 241-248. doi: 10.1016/j.ejphar.2004.07.055

Spencer, D. I., Robson, L., Purdy, D., Whitelegg, N. R., Michael, N. P., Bhatia, J., et al. (2002). A strategy for mapping and neutralizing conformational immunogenic sites on protein therapeutics. Proteomics 2, 271-279. doi: 10.1002/16159861(200203)2:3\%3C271::AID-PROT271\%3E3.0.CO;2-W

Steinberg, T. H., Newman, A. S., Swanson, J. A., and Silverstein, S. C. (1987). ATP4permeabilizes the plasma membrane of mouse macrophages to fluorescent dyes. J. Biol. Chem. 262, 8884-8888.

Stern, P., Behe, P., Schoepfer, R., and Colquhoun, D. (1992). Single-channel conductances of NMDA receptors expressed from cloned cDNAs: comparison with native receptors. Proc. Biol. Sci. 250, 271-277. doi: 10.1098/rspb.199 2.0159

Stoop, R., Thomas, S., Rassendren, F., Kawashima, E., Buell, G., Surprenant, A., et al. (1999). Contribution of individual subunits to the multimeric P2X(2) receptor: estimates based on methanethiosulfonate block at T336C. Mol. Pharmacol. 56, 973-981.

Surprenant, A., Rassendren, F., Kawashima, E., North, R. A., and Buell, G. (1996). The cytolytic P2Z receptor for extracellular ATP identified as a P2X receptor (P2X7). Science 272, 735-738. doi: 10.1126/science.272.5262.735

Taschenberger, H., Juttner, R., and Grantyn, R. (1999). Ca2+-permeable P2X receptor channels in cultured rat retinal ganglion cells. J. Neurosci. 19, 3353-3366.

Tatham, P. E., Cusack, N. J., and Gomperts, B. D. (1988). Characterisation of the ATP4- receptor that mediates permeabilisation of rat mast cells. Eur. $J$ Pharmacol. 147, 13-21. doi: 10.1016/0014-2999(88)90628-0 
Thomas, S. A., and Hume, R. I. (1990). Permeation of both cations and anions through a single class of ATP-activated ion channels in developing chick skeletal muscle. J. Gen. Physiol. 95, 569-590. doi: 10.1085/jgp.95.4.569

Torres, G. E., Egan, T. M., and Voigt, M. M. (1998a). N-Linked glycosylation is essential for the functional expression of the recombinant P2X2 receptor. Biochemistry 37, 14845-14851. doi: 10.1021/bi981209g

Torres, G. E., Egan, T. M., and Voigt, M. M. (1998b). Topological analysis of the ATP-gated ionotropic [correction of ionotrophic] P2X2 receptor subunit. FEBS Lett. 425, 19-23. doi: 10.1016/S0014-5793(98)00179-3

Torres, G. E., Haines, W. R., Egan, T. M., and Voigt, M. M. (1998c). Co-expression of P2X1 and P2X5 receptor subunits reveals a novel ATP-gated ion channel. Mol. Pharmacol. 54, 989-993.

Torres, G. E., Egan, T. M., and Voigt, M. M. (1999). Hetero-oligomeric assembly of P2X receptor subunits. Specificities exist with regard to possible partners. J. Biol. Chem. 274, 6653-6659. doi: 10.1074/jbc.274.10.6653

Toulme, E., Garcia, A., Samways, D., Egan, T. M., Carson, M. J., and Khakh, B. S. (2010). P2X4 receptors in activated C8-B4 cells of cerebellar microglial origin. J. Gen. Physiol. 135, 333-353. doi: 10.1085/jgp.200910336

Traynelis, S. F., Wollmuth, L. P., McBain, C. J., Menniti, F. S., Vance, K. M., Ogden, K. K., et al. (2010). Glutamate receptor ion channels: structure, regulation, and function. Pharmacol. Rev. 62, 405-496. doi: 10.1124/pr.109. 002451

Valera, S., Hussy, N., Evans, R. J., Adami, N., North, R. A., Surprenant, A., et al. (1994). A new class of ligand-gated ion channel defined by $\mathrm{P} 2 \mathrm{x}$ receptor for extracellular ATP. Nature 371, 516-519. doi: 10.1038/371516a0

Valera, S., Talabot, F., Evans, R. J., Gos, A., Antonarakis, S. E., Morris, M. A., et al. (1995). Characterization and chromosomal localization of a human P2X receptor from the urinary bladder. Receptors Channels 3, 283-289.

Villarroel, A., Burnashev, N., and Sakmann, B. (1995). Dimensions of the narrow portion of a recombinant NMDA receptor channel. Biophys. J. 68, 866-875. doi: 10.1016/S0006-3495(95)80263-8

Virginio, C., Church, D., North, R. A., and Surprenant, A. (1997). Effects of divalent cations, protons and calmidazolium at the rat $\mathrm{P} 2 \mathrm{X} 7$ receptor. Neuropharmacology 36, 1285-1294. doi: 10.1016/S0028-3908(97)00141-X

Virginio, C., MacKenzie, A., Rassendren, F. A., North, R. A., and Surprenant, A. (1999a). Pore dilation of neuronal P2X receptor channels. Nat. Neurosci. 2, 315-321. doi: 10.1038/7225

Virginio, C., MacKenzie, A., North, R. A., and Surprenant, A. (1999b). Kinetics of cell lysis, dye uptake and permeability changes in cells expressing the rat P2X7 receptor. J. Physiol. 519(Pt 2), 335-346. doi: 10.1111/j.1469-7793.1999.0335m.x
Virginio, C., North, R. A., and Surprenant, A. (1998). Calcium permeability and block at homomeric and heteromeric P2X2 and $\mathrm{P} 2 \mathrm{X} 3$ receptors, and P2X receptors in rat nodose neurones. J. Physiol. 510( $\mathrm{Pt} \mathrm{1),} \mathrm{27-35.} \mathrm{doi:}$ 10.1111/j.1469-7793.1998.027bz.x

Volonte, C., Apolloni, S., Skaper, S. D., and Burnstock, G. (2012). P2X7 receptors: channels, pores and more. CNS neurol. Disord. Drug Targets 11, 705-721. doi: $10.2174 / 187152712803581137$

von Kugelgen, I., Norenberg, W., Meyer, A., Illes, P., and Starke, K. (1999). Role of action potentials and calcium influx in ATP- and UDP-induced noradrenaline release from rat cultured sympathetic neurones. Naunyn. Schmiedebergs. Arch. Pharmacol. 359, 360-369. doi: 10.1007/PL00005362

Wiley, J. S., Chen, R., and Jamieson, G. P. (1993). The ATP4- receptor-operated channel (P2Z class) of human lymphocytes allows Ba2+ and ethidium + uptake: inhibition of fluxes by suramin. Arch. Biochem. Biophys. 305, 54-60. doi: 10.1006/abbi.1993.1392

Xu, X. J., Boumechache, M., Robinson, L. E., Marschall, V., Gorecki, D. C., Masin, M., et al. (2012). Splice variants of the P2X7 receptor reveal differential agonist dependence and functional coupling with pannexin-1. J. Cell Sci. 125, 3776-3789. doi: 10.1242/jcs.099374

Yan, Z., Li, S., Liang, Z., Tomic, M., and Stojilkovic, S. S. (2008). The P2X7 receptor channel pore dilates under physiological ion conditions. J. Gen. Physiol. 132, 563-573. doi: 10.1085/jgp.200810059

Zhou, H. X., and Cross, T. A. (2013). Influences of membrane mimetic environments on membrane protein structures. Annu. Rev. Biophys. 42, 361-392. doi: 10.1146/annurev-biophys-083012-130326

Conflict of Interest Statement: The authors declare that the research was conducted in the absence of any commercial or financial relationships that could be construed as a potential conflict of interest.

Received: 31 October 2013; accepted: 06 January 2014; published online: 05 February 2014.

Citation: Samways DSK, Li Z and Egan TM (2014) Principles and properties of ion flow in P2X receptors. Front. Cell. Neurosci. 8:6. doi: 10.3389/fncel.2014.00006 This article was submitted to the journal Frontiers in Cellular Neuroscience. Copyright (C) 2014 Samways, Li and Egan. This is an open-access article distributed under the terms of the Creative Commons Attribution License (CC BY). The use, distribution or reproduction in other forums is permitted, provided the original author(s) or licensor are credited and that the original publication in this journal is cited, in accordance with accepted academic practice. No use, distribution or reproduction is permitted which does not comply with these terms. 